\title{
METODOLOGÍA PARA LA ZONIFICACIÓN DEL RIESGO DE EROSIÓN EN CUENCAS ANDINAS. ESTUDIO DE CASO EN EL RÍO CHALACO, PIURA
}

\author{
Methodology for the zoning of the erosion risk in andean \\ basins. study of case in the river Chalaco, Piura
}

\author{
Laura Jiménez Callejo ${ }^{1}$, Pablo Martínez de Anguita ${ }^{2}$, María Ángeles Ruiz ${ }^{3}$, \\ María Sofía Dunin-Borkowski ${ }^{4}$ y Dante Guerrero ${ }^{5}$
}

Recibido 10/05/2006; aceptado el 15/09/2006

Resumen. El Fenómeno de El Niño azota violentamente de forma periódica el norte del Perú. Si bien localmente no se puede luchar contra él, se pueden amortiguar sus efectos. La enorme deforestación que sufren las cabeceras de cuencas andinas y las transformaciones agrarias, que constantemente empujan de la frontera agrícola a cotas más altas, favorecen los arrastres y avenidas, y dificultan la retención de agua. La falta de cartografía adecuada dificulta una planificación de usos del suelo que debería hacerse entre otros factores considerando el riesgo de erosión de las principales cuencas andinas. Se muestra un modelo de fácil aplicación a partir de escasa información cartográfica para ser aplicado en países en desarrollo para la estimación del riesgo de erosión a partir de datos georreferenciados y datos básicos disponibles habitualmente en los distintos servicios cartográficos nacionales. Este método se aplica en la Microcuenca de Mijal, en la cuenca del Chalaco, distrito de Piura, Perú, donde se analizan datos de pendiente, usos de la tierra y tipo de sustrato litológico, dando como resultado la zonificación de áreas en función del riesgo de erosión.

Palabras clave: erosión, planificación física, manejo de cuencas, países en desarrollo, El Niño

Abstract. El Niño atmospheric phenomenon produces periodically severe damages in the North of Peru. Although at a local level is not possible to stop it, their effects can be mitigated. Due to the forward-moving agricultural frontier in the mountainous areas of the Peruvian Andes, woods are disappearing. This woods reduction cause intense soil erosion processes in grounds that lead to a poor vegetative cover and a high level of surface drainage capacity. The lack of an adequate cartography complicates land use planning that should be done according to the erosion risk among other factors in these river basins. A risk of erosion model based on georeferred data and easy to replicate in developing countries with a small number of cartography layers available is here presented. This method was applied to the micro basin of Mijal, in the Piura river Basin, Perú. Slope, land use and litology are analyzed in order to establish a risk erosion zonification model. Key Words: erosion, land use planning, basin management, developing countries, El Niño

Dpto. de Tecnología Química y Ambiental, Universidad Rey Juan Carlos. C/ Tulipán s/n. 28933 Móstoles, Madrid. inmaculada.gomez@urjc.es

2. Dpto. de Tecnología Química y Ambiental, Universidad Rey Juan Carlos. C/ Tulipán s/n. 28933 Móstoles, Madrid. pablo.martinezdeanguita@urjc.es

3. Dpto de Tecnología Ouímica y Ambiental, Universidad Rey Juan Carlos. C/ Tulipán s/n. 28933 Móstoles, Madrid.maria.ruiz@urjc.es

4. Facultad de Ingenieria, Universidad de Piura. Avda. Ramón Mújica 131.Urb. San Eduardo. Piura, Perú. gis@udep.edu.pe

5. Facultad de Ingeniería, Universidad de Piura. Avda. Ramón Mújica 131. Urb. San Eduardo. Piura, Perú. dguerrero@udep.edu.pe 


\section{INTRODUCCIÓN}

Los efectos que produce el Fenómeno de El Niño pueden ser mitigados si en las cabeceras de cuencas se logra una planificación adecuada de los usos y ésta es mantenida en el tiempo, lo cual requiere la participación activa de los campesinos. En este trabajo solo se afronta la primera cuestión. La segunda debería ser abordada estudiando los costes de transformación y encontrándose la fuente de financiación adecuada. En este sentido, este trabajo ha sido realizado como primer paso dentro de la elaboración de un sistema de Pago por Servicios Ambiéntales (PSA). Un sistema PSA es un mecanismo flexible y adaptable a diferentes condiciones, que apunta a un pago o compensación directo por el mantenimiento o provisión de un servicio ambiental, por parte de los usuarios del servicio el cual se destina a los proveedores (Martínez de Anguita y Beneitez, 2005). En este caso el servicio ambiental consistiría en el suministro de agua potable y la disminución del riesgo de grandes avenidas a las ciudades del Norte de Perú afectadas (Sullana y Piura) empleando dichos fondos en la conservación de los bosques productores, en la ordenación y gestión de las cuenca hidrográficas en las que se hallan y en el desarrollo local de sus habitantes. La idea fundamental de los sistemas de PSA es crear un mercado para un servicio ambiental que habitualmente no tiene precio. El sistema parte de la identificación de agentes económicos responsables de la ex- ternalidad ambiental positiva, los "proveedores" del servicio, y de los agentes beneficiados o usuarios, en este caso, los campesinos (DE HEK et al 2004).

El primer paso para establecer un mecanismo de este tipo es por lo tanto estimar los procesos de erosión de suelos y elaborar una planificación de usos del suelo que disminuya el riesgo e incremente la capacidad de retención de los suelos. Se desea además hacerlo con una base cartográfica pequeña pero disponible en cualquier cuenca andina.

Además de la mitigación del fenómeno de El Niño, existen otras razones para cartografiar de un modo sencillo los riesgos de erosión en montañas andinas. La erosión es uno de los principales problemas ambientales a nivel mundial, pero su avance y repercusión se hace mas patente en los países subdesarrollados, que a causa de su pobreza no toman medidas para frenarla. En Perú, la erosión hídrica es un problema para la producción agrícola, ya que ha reducido la cantidad de tierras cultivables. Sin embargo, son muy pocos los datos cuantitativos de erosión que están disponibles, así como la existencia de una escasa compresión de los procesos y causas que promueven la erosión en las áreas andinas.

\section{2. ÁREA DE ESTUDIO}

El Distrito ${ }^{6}$ de Chalaco es centro político y administrativo de la subcuenca ${ }^{7}$ del río Chalaco, y se localiza en la Sierra de Piura. Es un ecosistema de montaña muy frágil, pero vital

Figura 1. Ubicación del Distrito de Chalaco en Perú y en Morropón.
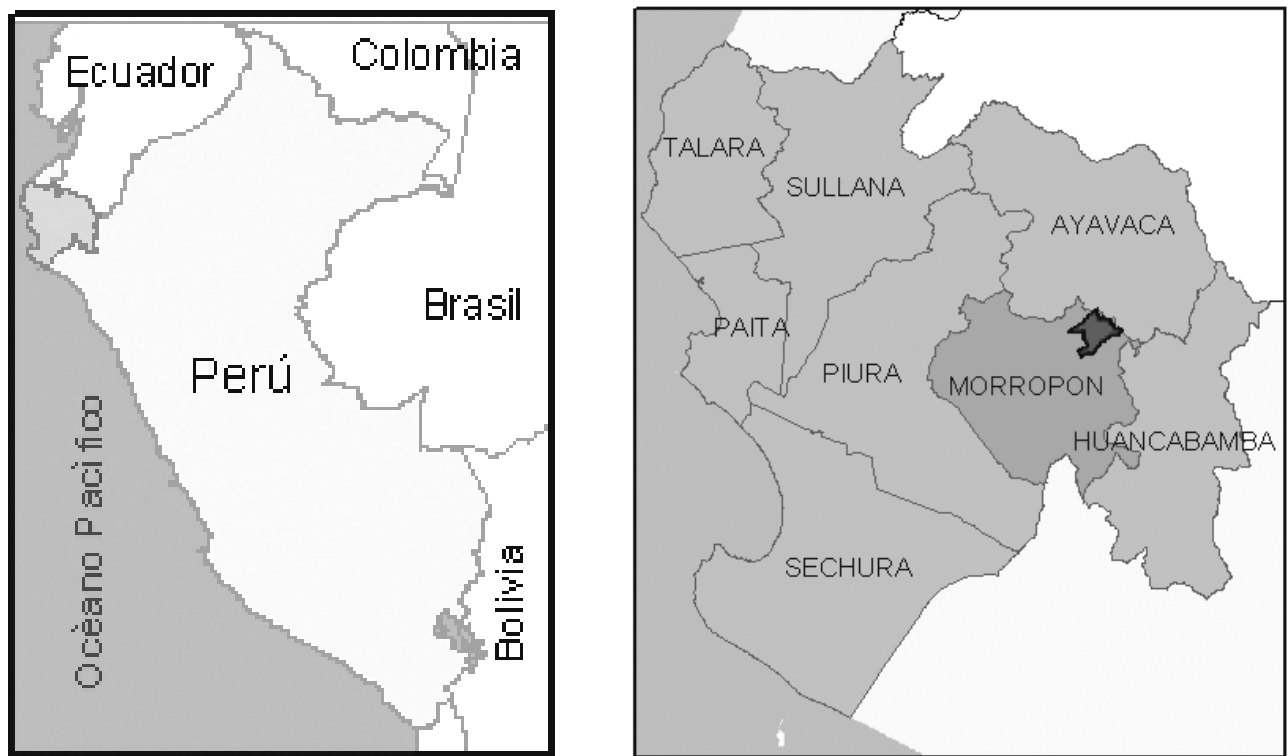

Fte. Programa desarrollo sostenible de ecosistemas de montaña en Perú

6. Distrito, cada una de las demarcaciones en que se subdivide un territorio

7. Subcuenca, es toda área que desarrolla su drenaje directamente al curso principal de la cuenca. Varias subcuencas pueden conformar una cuenca. 
para el desarrollo la Región de Piura por su gran potencial en recursos naturales que en la actualidad se encuentran en peligro de extinción debido a la sobreexplotación de los mismos por parte de los pobladores que viven en condiciones de extrema pobreza.

El distrito de Chalaco está ubicado $145 \mathrm{~km}$ al noreste de la ciudad de Piura, en la provincia de Morropón, y forma parte de la Micro Región Andino Central (Martín Guerrero, 2005). Chalaco se sitúa en la vertiente occidental de la Cordillera de los Andes, formando parte de la Región de Piura, a $1085 \mathrm{~km}$ al norte de Lima. Cuenta con una densidad poblacional de $79.8 \mathrm{hab} / \mathrm{km}^{2}$ tiene una superficie aproximada de $140 \mathrm{~km}^{2}$ y engloba las Microcuencas ${ }^{8}$ de Cerro Negro, Los Potros, Mijal, Ñoma y Nogal (Figura 1).

La Microcuenca Mijal está ubicada en la sierra de la Región de Piura, en la vertiente occidental de los andes piuranos. Forma parte de la subcuenca del río Chalaco, que a su vez integra la cuenca del río Piura. Esta última nace en las subcuencas de las zonas altas de la vertiente occidental de los andes piuranos y atraviesa la zona central de la Región hasta el desierto de Sechura en la zona de la costa.

La Microcuenca Mijal tiene una superficie total de $3.064,86$ hectáreas, y está integrada por 8 centros poblados.

\subsection{Descripción de las características del medio físico}

La Microcuenca de Mijal (Figura 2) forma parte del espacio natural de la naciente de la subcuenca del río Chalaco, afluente de la cuenca del río Piura en la vertiente nororiental del Océano Pacífico. Tiene una vital importancia para el mantenimiento del ecosistema de la región Piura y en particular para la zona ubicada en la zona alta de la subcuenca del río Chalaco, debido a que esta zona aún cuenta con una área considerable de bosque nativo en la naciente, el bosque de Mijal, con una extensión de 134,5 hectáreas aproximadamente.

La totalidad de la Microcuenca Mijal cuenta con una fisiografía muy accidentada (Figura 3), lo cual no ha sido obstáculo para que la agricultura se lleve a cabo en estas zonas. El proceso de expansión de la frontera agrícola es continuo, llevándose a cabo esta actividad en zonas de pendiente extremadamente pronunciada,

Según Peña (2003), los suelos que forman la zona alta son pedregosos, arenosos y de color oscuro. Los de la zona media son franco-arenosos y erosionables. Son suelos empobrecidos debido a la sobreexplotación productiva, ya que

FIGURA 2. Microcuencas que forman el Distrito de Chalaco.

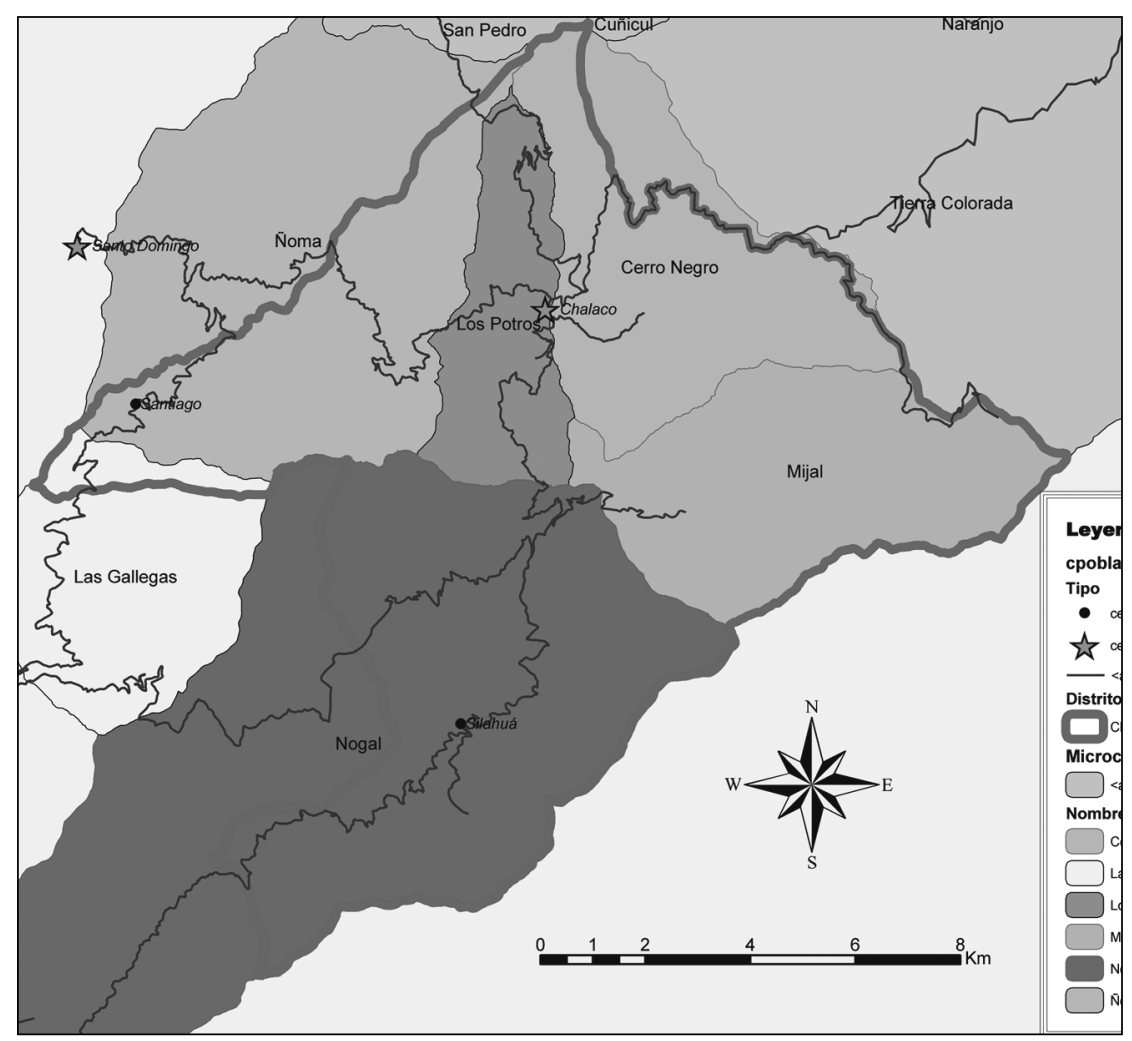

Fte. Programa desarrollo sostenible de ecosistemas de montaña en Perú.

8. Microcuenca, es toda área que desarrolla su drenaje directamente a la corriente principal de una subcuenca. Varias microcuencas pueden conformar una subcuenca. 
Figura 3. Fisiografía de Chalaco.

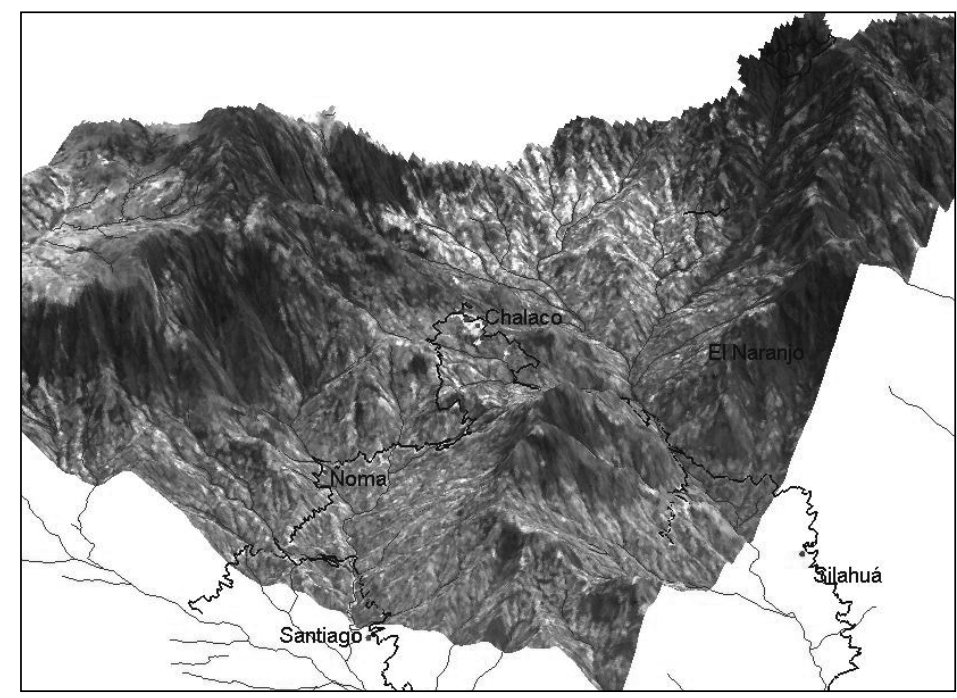

Fte. Servicio cartográfico de la Universidad de Piura.

se realizan continuas quemas de parcelas sin tener en cuenta ninguna práctica de conservación del suelo. Por último, la zona baja presenta suelos con textura franco-arcillosa. Éstos son fértiles y su calidad se conserva, aunque presenta problemas puntuales de deslizamiento de suelo originando cárcavas.

En general, son suelos residuales ${ }^{9}$ producto de la meteorización y del intemperismo, así como de la estructuración del suelo y la composición litológica de los diferentes tipos de rocas que afloran en la microcuenca (0caña, 2004).

Hace unos años, la principal cobertura del suelo fue boscosa, una evidencia de esto es la presencia de los materiales utilizados en la construcción de viviendas, entre los cuales se encuentran vigas de árboles de grandes dimensiones. Esta cobertura boscosa era la que protegía los suelos residuales de la erosión. Actualmente, hay suelos desprotegidos y de poca profundidad ya que se realiza agricultura permitiendo la erosión de los suelos debido a la poca profundidad de las raíces de los cultivos.

La capacidad de uso mayor de los suelos es de protección, forestal y con zonas para cultivos (Tabla 1)

La vegetación de la zona alta se caracteriza por el bosque nublado de montaña de Mijal (Figura 4). De acuerdo al Sistema de Clasificación de Zonas de vida propuesto por L.R. Holdridge y el Mapa Ecológico de Perú, se pueden distinguir dos pisos bioclimáticos:

- Bosque muy húmedo montano tropical

- Bosque húmedo montano bajo tropical
La Microcuenca Mijal cuenta con 8 caseríos $^{10}$ : Sánchez Cerro, Juan Velasco, Carpinteros, Naranjo, Portachuelo, Francisco Bolognesi, Laguna de Mijal y Vista Alegre. Todos ellos están enmarcados políticamente en el Distrito de Chalaco (provincia de Morropón, Región de Piura). La población estimada en 2003 es de 1.913 personas, lo que implica aproximadamente un total de 422 familias (con un tamaño promedio de las mismas de 5.34 miembros).

TABLA 1. Capacidad de uso mayor de la Microcuenca Mijal

\begin{tabular}{|l|c|}
\hline Categoría & Hectáreas \\
\hline Agricultura & 84.7 \\
\hline Agroforesteria $^{11}$ & 198.1 \\
\hline Pastos $^{11}$ & 137.4 \\
\hline Silvopasturas $^{12}$ & 473.8 \\
\hline Protección $^{\prime}$ & 483.3 \\
\hline Reforestación & 446.5 \\
\hline Otros & 37.1 \\
\hline
\end{tabular}

Fte. Sistema de Información Geográfica (SIG). Programa de Desarrollo Sostenible de ecosistemas de Montaña en el Perú (2003).

Es una zona en la que el bosque nublado está desapareciendo debido a la necesidad de los habitantes por cultivar nuevas tierras para autoconsumo. Al deforestar desaparecen el ecosistema y la biodiversidad autóctona de la zona.

Además, el agua de lluvia no encuentra un sustrato de bosque que la retenga el tiempo necesario para ser absorbida por el suelo y por tanto se reduce el caudal de los ríos durante la mayor parte del año (esto no sólo afecta a la zona,

9. Suelos residuales, es el suelo que cubre la roca de la cual se deriva. En consecuencia no es suelo transportado.

10. Caserío, conjunto de casas.

11. Agroforestería, sistema en el que se combinan árboles y/o arbustos y cultivos en el mismo sitio.

12. Silvopasturas, sistema en el que se combinan árboles y/o arbustos, ganado y pradera en un mismo sitio. 
FIgURA 4. Sur del Bosque de Cyateas. Algunas especies presentes: Limoncillo, Shivato, Paltaguiro.

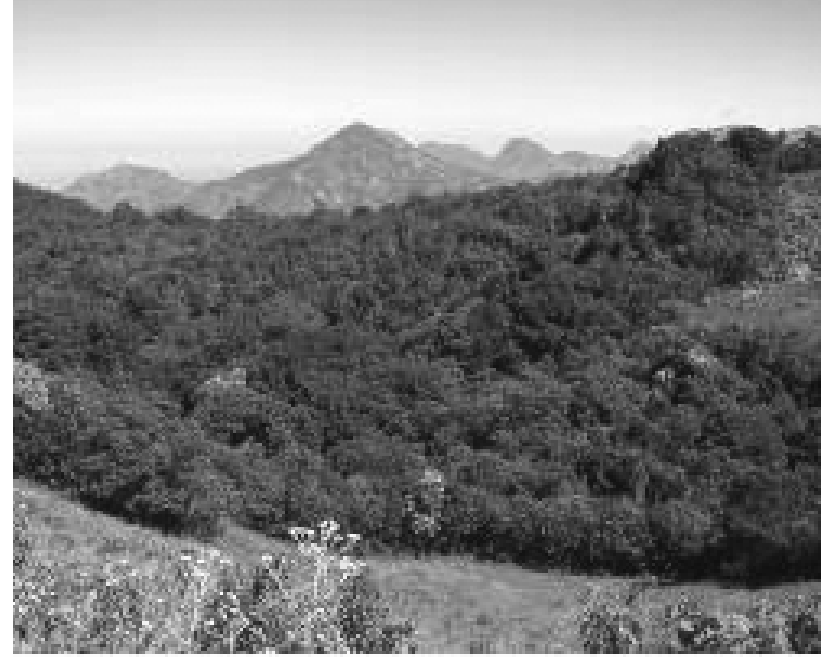

sino a toda la cuenca del río). Por otra parte, al desaparecer la vegetación que sujeta el terreno, cuando la lluvia cae con fuerza, el agua destroza los cultivos de ladera y arrastra piedras y barro provocando inundaciones y crecidas repentinas que asolan los pueblos de la zona más baja del río. El fenómeno del Niño, que tiene lugar en esta zona del Perú, es un fenómeno cíclico que ha ocurrido siempre. Actualmente tiene efectos devastadores porque es un fenómeno que se ve potenciado por la deforestación de los ecosistemas de montaña.

\subsection{Objetivos}

El modelo de desarrollo económico imperante en la región ha supuesto un alto coste para el medio ambiente. La superficie boscosa de Mijal está decreciendo como consecuencia de la introducción de cultivos y ganado, lo que provoca que el suelo se esté perdiendo. La erosión es uno de los principales problemas ambientales a nivel mundial, pero su avance y repercusión se hace mas patente en los países subdesarrollados, que a causa de su pobreza y su desconocimiento no toman medidas para frenarla.

En Piura ya se ha tomado conciencia de los efectos de la erosión, debido principalmente a las devastadoras consecuencias que el fenómeno del Niño deja a su paso. La erosión es un fenómeno natural pero que se acrecienta por causas antrópicas. La gravedad del problema queda patente cuando se observa que el $80 \%$ de los bosques naturales de esta cuenca están deforestados. Por tanto, los suelos destinados al bosque pero que se usan actualmente para agricultura están en franco proceso de deterioro de erosión, y como consecuencia los niveles de rendimiento de los cultivos se ven cada vez mas disminuidos.

El problema se agrava debido a que los niveles tecnológicos para la producción agropecuaria son bajos, a que se

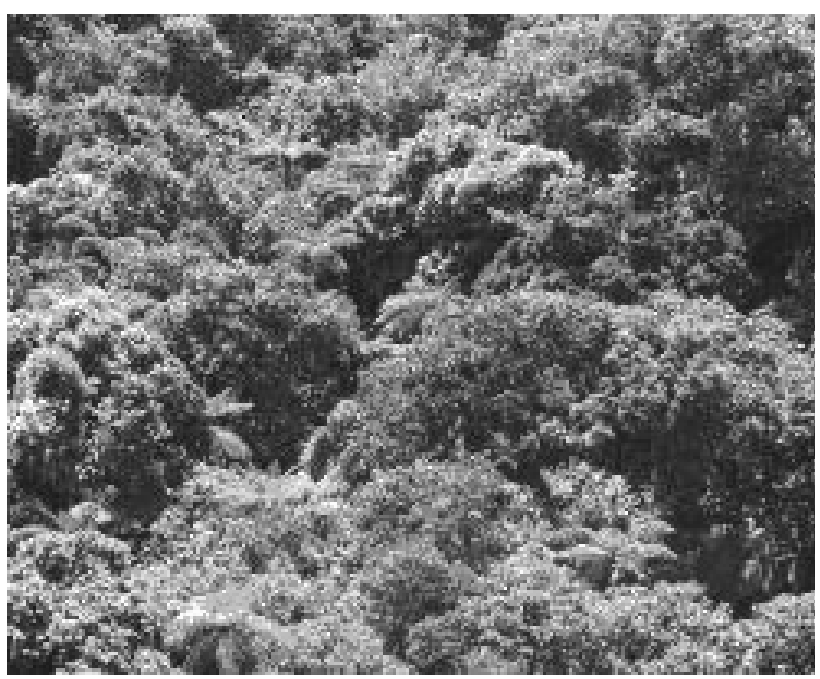

han abandonado prácticas ancestrales de manejo racional del espacio y los recursos, y a que se tiene poco conocimiento acerca del potencial económico y comercial de los recursos y productos de la cuenca.

Además, todo ello se ve incrementado por el limitado acceso a la información de la población de Chalaco, que hace que conciban las actividades productivas de la zona para una economía de subsistencia.

Lo que se pretende con este estudio es la identificación de los puntos vulnerables a la erosión, y su posterior protección mediante medidas de conservación de suelos o cambios en la localización de los usos. así mayor productividad en sus cultivos.

Además, la metodología que se elabore podrá ser extrapolada a toda la cuenca del Piura. Con ello se disminuirá la pérdida de suelo que repercutirá sobre:

- La ciudad de Piura: los efectos del fenómeno del Niño en esta ciudad no serán tan devastadores debido a la mayor retención de agua en la cabecera (Microcuenca de Mijal).

- Productividad de los suelos: los campesinos podrán localizar sus cultivos en las zonas menos vulnerables, consiguiendo

El resultado esperado de la realización del presente estudio de erosión será un Mapa de Zonificación de Riesgo de Erosión a fin de facilitar una herramienta para la prevención de la erosión para la población rural y para los planificadores.

El ámbito territorial del presente estudio comprende el área de la Microcuenca de Mijal con una extensión de 3.064 hectáreas. Debido a su situación de cabecera de la subcuenca del río Chalaco en la cuenca del río Piura su área total de influencia es mucho mayor. 


\section{MATERIAL Y MÉTODOS}

\subsection{Datos disponibles}

La falta de información sobre la zona de estudio ha sido unos de los factores limitantes para aplicar una metodología válida, esto ha condicionado el establecimiento del método de trabajo y los resultados obtenidos.

La información base de la que se parte es la recogida durante el trabajo de campo realizado en la zona. Ésta se complementa con los siguientes mapas ya elaborados:

- Mapa de Uso de la tierra, fue obtenido a partir de dos imágenes Landsat ETM vecinas, de los años 2001 y 2000 (fin de la época de estiaje).

- Modelo Digital del Terreno realizado por el servicio geológico checo a partir de imágenes SRTM de 25 metros de resolución.

- Mapa geológico elaborado por el servicio geológico checo.

- Mapa de vulnerabilidades, donde están ubicados posibles procesos geodinámicos, hechos por científicos checos.

- Mapa político elaborado por el servicio cartográfico de la Universidad de Piura.

- Mapa de pre-zonificación realizado por el servicio cartográfico de la Universidad de Piura.
- Mapa de vulnerabilidad a los desastres elaborado por el servicio geológico checo en el año 2005.

La integración de los datos alfanuméricos y los mapas ha sido posible gracias al Sistema de Información Geográfica Arcview 3.2.

\subsection{Metodología}

Actualmente existe un gran número de modelos disponibles para estimar los procesos erosivos. Esta diversidad de modelos implica que debe determinarse cuál de ellos será el más apropiado para cada caso en función de los datos disponibles, la escala espacial y temporal.

La erosión, por su distribución espacial y porque está condicionada por muchos factores interrelacionados, es un proceso que no puede ser medido de forma exacta y de manera sencilla al mismo tiempo. En este caso, la carencia de información significativa debida a la situación de la zona, determina en gran medida la exactitud alcanzable con respecto a la erosión.

El método ideal para la estimación del riesgo de erosión debe tener en cuenta los principales factores que afectan a la erosión; según el Método de Albaladejo et al. (1998) son los que se muestran en la Figura 5.

FIGURA 5. Factores que afectan a la erosión.

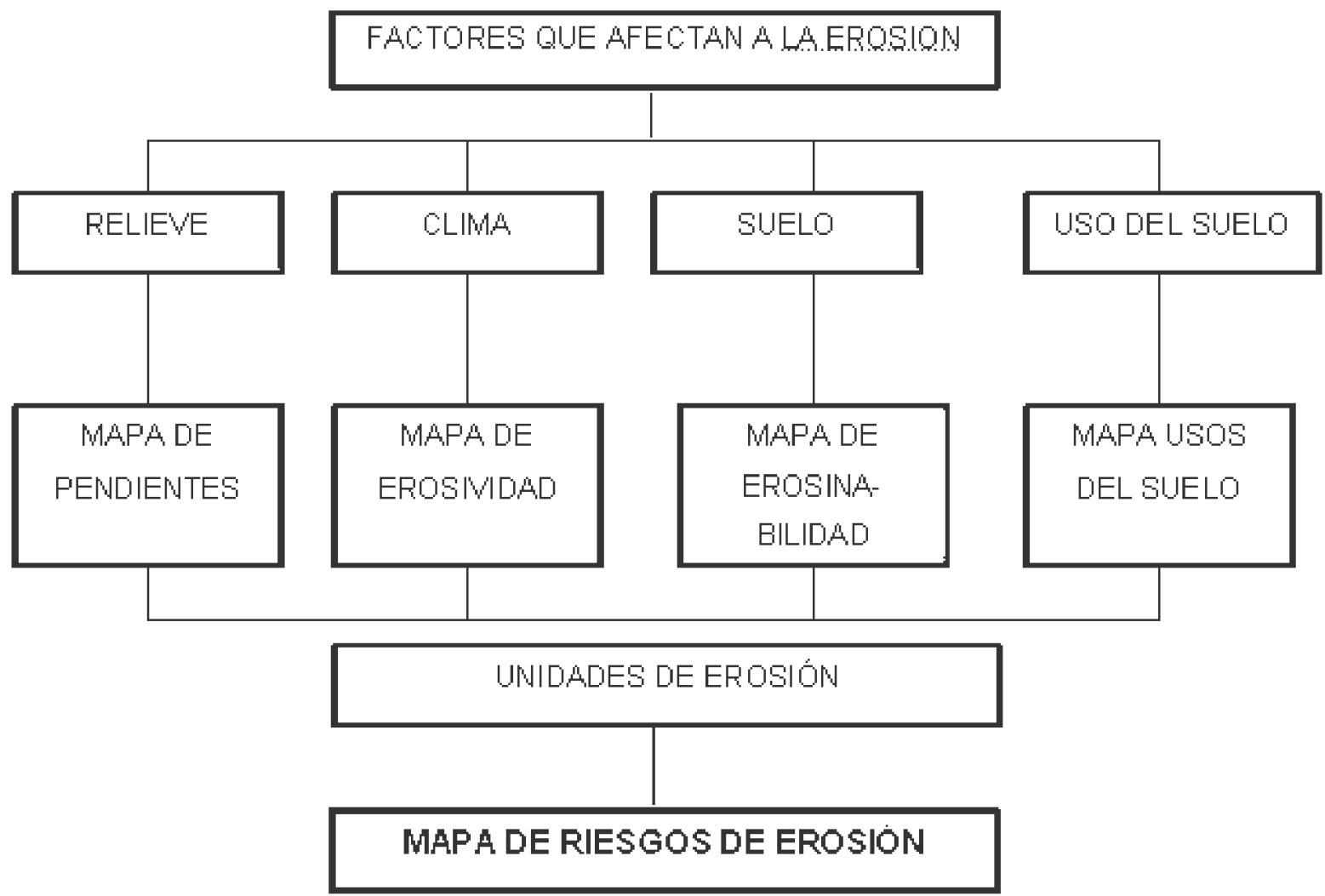

Fte: Guía para la elaboración de estudios del medio físico. 
En este caso, debido a la escasez de datos y mapas disponibles, se ha optado por realizar una estimación cualitativa del riesgo de erosión en la zona, ya que para aplicar un modelo cuantitativo relativamente sencillo, como pueda ser la ecuación de la USLE (Universal Soil Loss Equation), los datos eran insuficientes. Faltaban datos climatológicos, y datos sobre el tipo de suelo.

La secuencia de pasos llevada a cabo para la elaboración de este estudio es la que se ilustra en la Figuras 6 y 7
Si bien hay varios factores que influyen en el riesgo de erosión en una cuenca, para lograr el objetivo de este estudio se hace un análisis simple poniendo énfasis en dos variables que tienen estrecha relación con el grado de la erosión (FAO, 1993): pendientes y uso de la tierra (cobertura vegetal).

El factor pendiente es probablemente el factor más determinante en un área con pendientes tan acusadas y el factor uso del suelo permite enfocar a las áreas más afectadas

Figura 6: Esquema de la metodología.

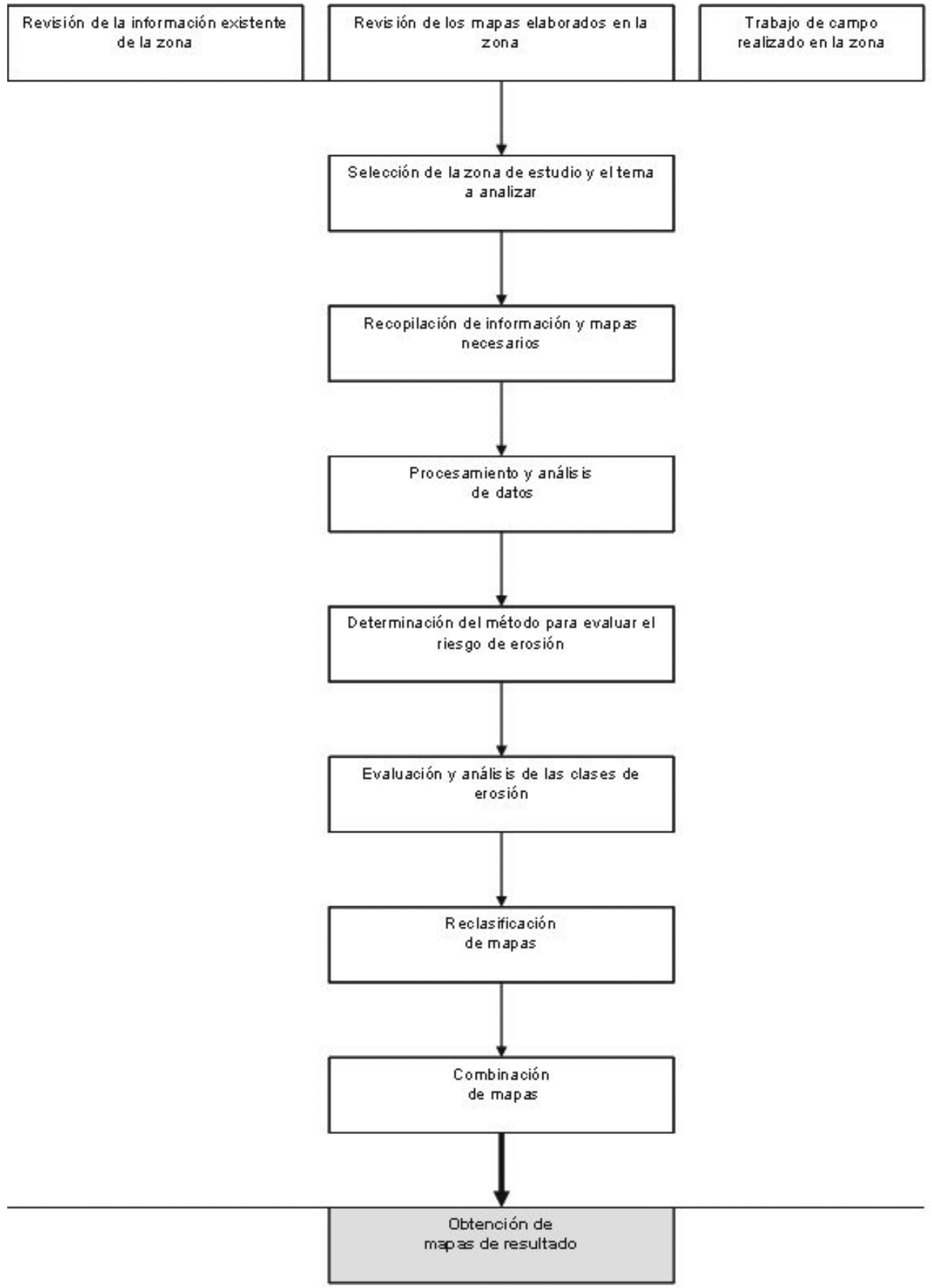


FIGURA 7. Modelo Cartográfico.
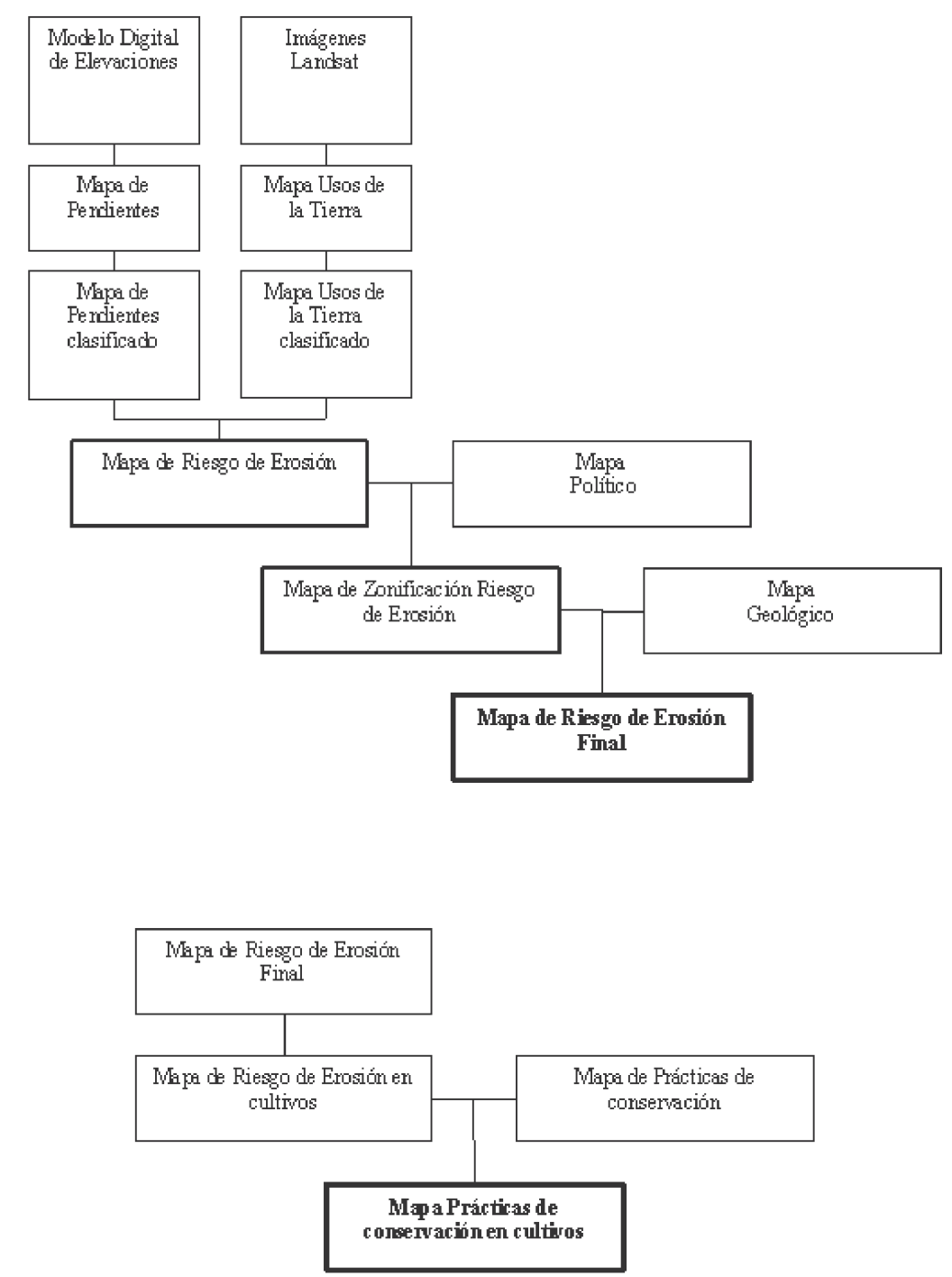

Mapas resultado

(suelos sin vegetación) y con más potencial de ser afectados (cultivos).

Para establecer el riesgo de erosión en la Microcuenca de Mijal se integran el mapa de pendientes y el mapa de usos de la tierra. Cada mapa proporciona información de un factor relevante frente a la erosión y se estructuran en cinco clases como muestra la Tabla 2. Estas clases hacen referencia a las condiciones que afectan al riesgo de erosión, siendo la pri-

TABLA 2. Clases de riesgos de erosión.

\begin{tabular}{|c|l|}
\hline Clase & Riesgo de erosión \\
\hline 1 & Muy bajo \\
\hline 2 & Bajo \\
\hline 3 & Medio \\
\hline 4 & Alto \\
\hline 5 & Muy alto \\
\hline
\end{tabular}

Fte. Elaboración propia mera de ellas (clase 1) la que menos contribuye a la pérdida de suelo.

Para poder llevar a cabo la integración del mapa de pendientes y el mapa de uso de la tierra, éstos son reclasificados según las clases establecidas en la Tabla 2. Para esta operación se ha consultado bibliografía y estudios realizados en zonas cercanas y similares sobre la erosión. Esta tarea ha resultado compleja debido a la escasez de datos y estudios sobre este aspecto en Perú.

De la combinación de los dos mapas se obtiene una matriz de $5 \times 5$ que representa los valores de riesgo de erosión teniendo en cuenta la pendiente y el uso de la tierra.

Con el propósito de que el mapa resultado ayude a establecer el diálogo con los campesinos y líderes políticos, éste se cruzará con un mapa del Distrito de Chalaco en el que figuren las divisiones territoriales de las Microcuencas y caseríos. El resultado de la combinación de ambos mapas será el 
Mapa de Zonificación de Riesgo de erosión. La zonificación del mapa de riesgo de erosión es posterior al análisis, puesto que su finalidad es servir como herramienta de planificación a la administración y organización.

Posteriormente, este mapa se combinará con el mapa geológico de la zona, para poder identificar las zonas que incrementan o mantienen su riesgo de erosión en función del tipo de roca presente. De esta forma, el riesgo de erosión no sólo queda determinado por la pendiente y por el uso del suelo.

El mapa geológico es previamente clasificado en dos categorías, una de ellas tomará el valor 0 e incluye las rocas que tengan un riesgo de erosión muy bajo, y la segunda categoría tomará el valor 1, puesto que representa un tipo de roca con mayor riesgo de erosión.

De la suma de los dos mapas se obtiene una matriz de $5 \times 2$ que representa los valores de riesgo de erosión teniendo en cuenta el tipo de roca. Este hecho ocasiona que algunos valores se incrementen en una unidad, y otros sin embargo, mantengan su riesgo de erosión.

Finalmente, a partir de este mapa se sugerirán zonas prioritarias de actuación y medidas a tomar para disminuir el riesgo de erosión en la Microcuenca de Mijal.

Para las clasificaciones de mapas se han usado principalmente datos secundarios (tomados de diversos estudios) y datos originales (tomados de la Universidad de Piura y elaboración propia). Aunque se podría discutir mucho sobre lo que constituye un conjunto mínimo de datos, el punto principal que se ha buscado es que sea un método que pueda desarrollarse en poco tiempo, con un coste relativamente bajo y que permita distinguir áreas con distintos peligros de erosión. En definitiva, se trata de una propuesta flexible que sirva para iniciar el proceso de concienciación de la población local y sus líderes políticos. Este será el paso inicial para seguir trabajando en posteriores estudios para la consecución de más datos que permitan calcular de forma cuantitativa la pérdida de suelo.

En base al Modelo Digital de Elevaciones (véase Figura 8) se generó el Mapa de Pendientes. Las pendientes pueden ser calculadas en porcentajes o en grados sexagesimales $\left(45^{\circ}\right.$ $=100 \%$ ), en este caso se calculan en porcentajes para una interpretación de los resultados más directa. El resultado del cálculo de pendientes en la zona engloba valores de 0 hasta más del $150 \%$ como muestra la Figura 9.

Los intervalos de las pendientes son agrupados en cinco clases atendiendo a su repercusión sobre el riesgo de erosión como muestra la Tabla 3

Estos intervalos de pendientes han sido tomados del estudio «Priorizando Áreas para la conservación de suelos en la Microcuenca de la Encañada (Cajamarca, Perú)" dirigido por el Consorcio para el Desarrollo Sostenible de la Ecoregión Andina (CONDESAN), y llevado a cabo en el año 2002.

La selección de este trabajo para definir los intervalos de pendientes en la zona de estudio recae en la semejanza climatológica de las zonas, y también, a que la finalidad de ambos es la misma, la elaboración de un mapa de riesgo de erosión.

Se ha considerando que cuanto mayor es el porcentaje de pendiente mayor será la erosión del suelo. Un aumento del ángulo de la ladera causa un aumento de la velocidad de escorrentía y con ello la energía cinética del agua que causa un mayor arrastre de las partículas del suelo, definiéndose las siguientes clases:

FiguRA 8. Modelo Digital de Elevaciones.

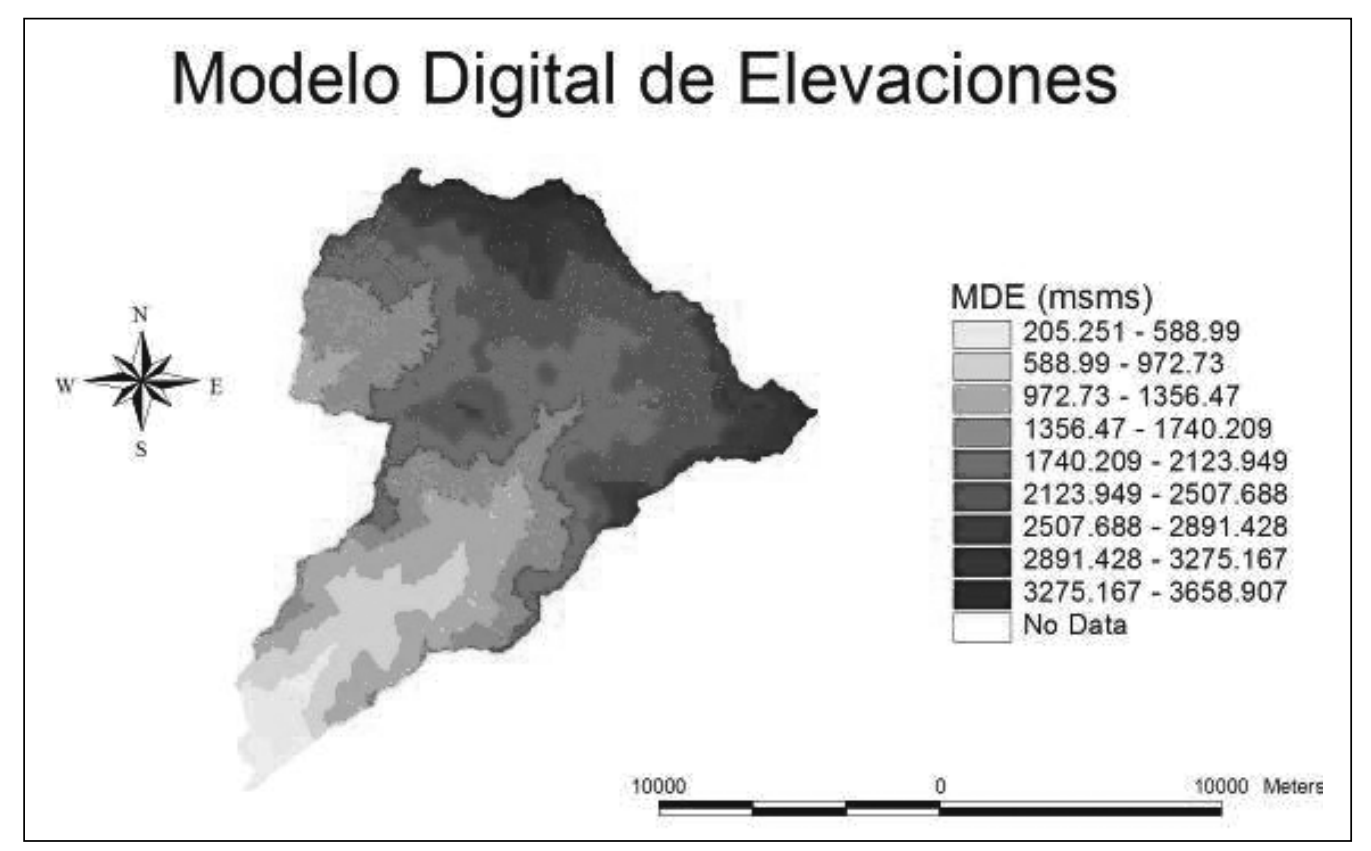


Figura 9. Mapa de Pendientes en el Distrito de Chalaco.

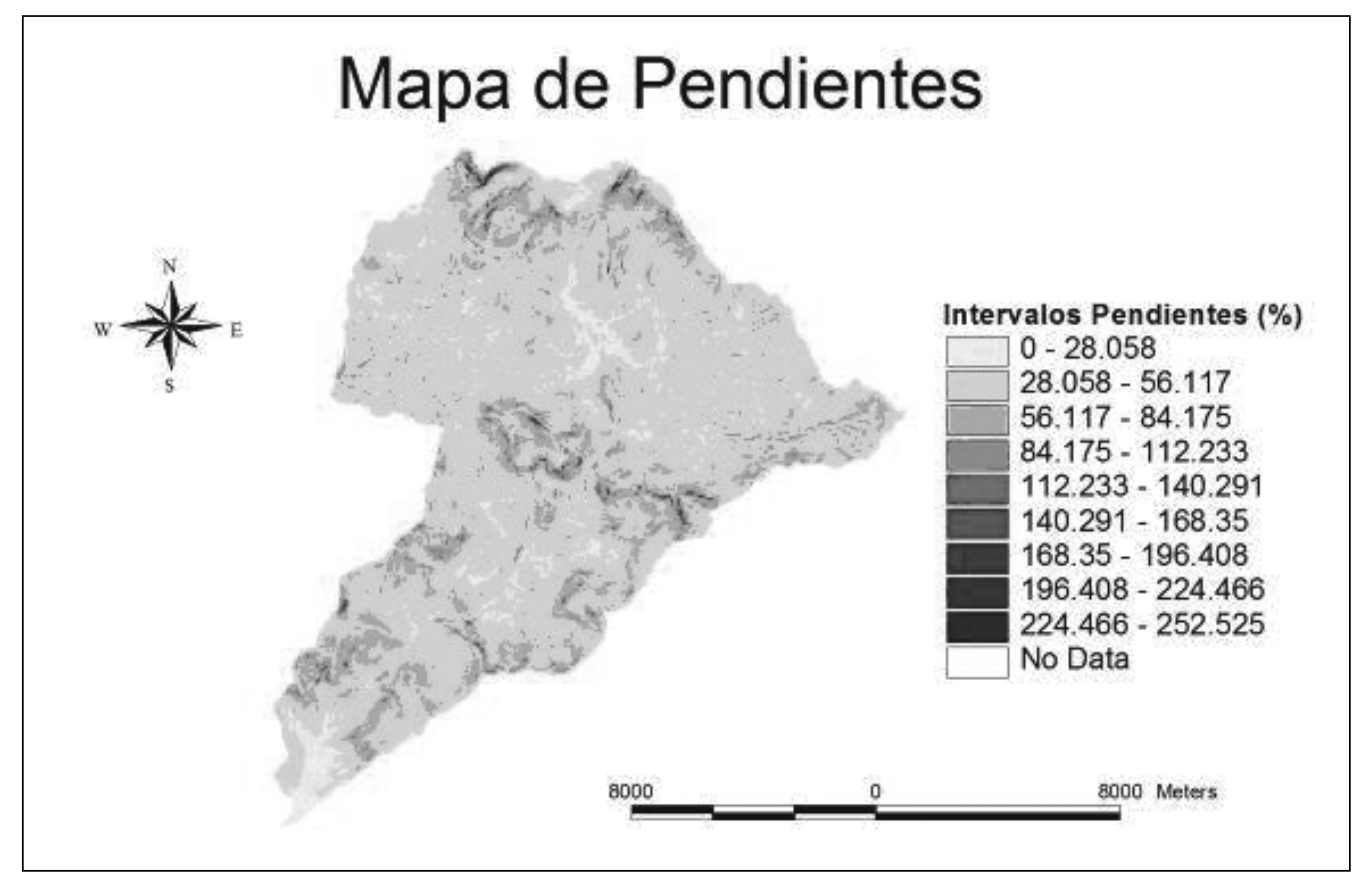

TABLA 3. Clasificación de pendientes

\begin{tabular}{|c|c|c|}
\hline Clase & Pendiente (\%) & Riesgo de erosión \\
\hline 1 & $0-10 \%$ & Muy bajo \\
\hline 2 & $10-20 \%$ & Bajo \\
\hline 3 & $20-40 \%$ & Medio \\
\hline 4 & $40-60 \%$ & Alto \\
\hline 5 & $>60 \%$ & Muy alto \\
\hline
\end{tabular}

Fte. Elaboración propia

- Clase 1: Pendientes de 0 a $10 \%$, son áreas relativamente planas donde no habrá pérdidas considerables de suelo, independientemente del tipo de uso o de la presencia de lluvias intensas, por tanto el riesgo de erosión es muy bajo.

- Clase 2: Pendientes de 10 a $20 \%$, son zonas donde la erosión que se presenta es baja, y ésta se puede controlar con prácticas de manejo adecuadas.

- Clase 3: Pendientes de 20 a $40 \%$, el riesgo de erosión es más alto y los tipos de usos del suelo ya están limitados.

- Clase 4: Pendientes de 40 a $60 \%$, se considera como riesgo de erosión alto y por tanto son zonas no aptas para la agricultura por las pérdidas de suelo que conlleva independientemente del tipo de suelo, intensidad de lluvias, etc. Además de los problemas de erosión, las áreas con pendientes agudas también presentan un menor potencial de uso agrícola.

- Clase 5: Pendientes mayores de $60 \%$, son zonas con un riesgo de erosión muy elevado debido a la alta velocidad adquirida por el agua, y por consiguiente de su energía cinética provocando un mayor arrastre de partículas.

Para la consecución del mapa de pendientes clasificado (Figura 10) ha sido necesario, en primer lugar, transformar el modelo digital de elevaciones en un mapa de pendientes mediante un Sistema de Información Geográfica (Arcview 3.2). Posteriormente, el mapa de pendientes obtenido se ha clasificado en las cinco clases definidas anteriormente en la Tabla 3.

\section{CARTOGRAFÍA GENERADA}

\subsection{Clasificación de los usos del suelo en relación al riesgo de erosión}

La pérdida del suelo está relacionada con las lluvias, en parte a través del poder disgregante de las gotas de Iluvia que golpean la superficie del suelo, y por otra parte a través de la contribución de la lluvia a la escorrentía. Por esta razón, parece obvia la relación existente entre un mayor o menor grado de cobertura vegetal (determinada por el uso del suelo) con un menor o mayor, respectivamente, riesgo de erosión. Una cobertura sobre el suelo lo protege de la fuerza de las gotas de lluvia y disminuye la separación de las partículas de los agregados de suelo, que es el primer paso en el proceso de erosión hídrica. Según el «Manual de prácticas integradas de manejo y conservación de suelos", una cobertura del suelo del $40 \%$ reduce las pérdidas de suelo a valores menores de $10 \%$ de lo que ocurriría en el mismo suelo desnudo (FA0, 1997). Además, la protección del suelo debido a la co- 
Figura 10. Mapa de Pendientes clasificado en el Distrito de Chalaco.

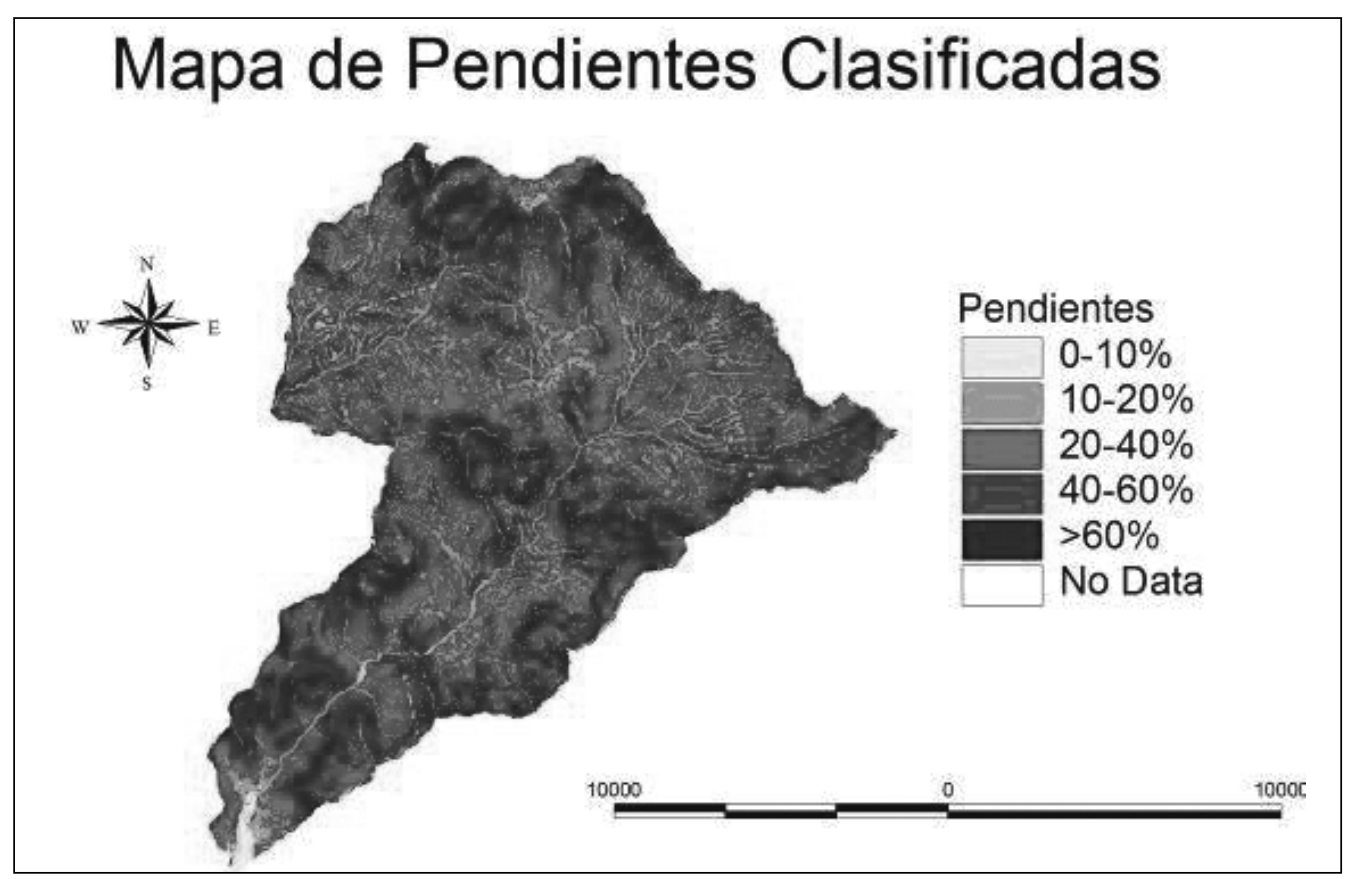

bertura evita la formación de costras y mantiene una mayor tasa de infiltración.

El Mapa de Uso de la tierra (Figura 11) representa seis usos de la tierra, que se agrupan en cinco categorias según se muestran en la Tabla 4. El establecimiento y orden de repercusión de éstas respecto al riesgo de erosión se ha realizado mediante un análisis de los resultados de los siguientes estudios: «Aplicaciones del modelo USLE/RUSLE para estimar pérdidas de suelo por erosión en Uruguay y la región sur de la cuenca del río de la Plata", "Erosión del suelo en los lados de la Cordillera Real (Sur de Ecuador)" y "Priorizando Áreas para la Conservación de Suelos en la Microcuenca La Encañada (Perú)».

Existe una variabilidad entre la erosión potencial para cada tipo de uso de la tierra, es decir, no todos los bosques, pastizales y cultivos se encuentran en el mismo estado. No se

Figura 11. Mapa de Usos de la tierra del Distrito de Chalaco.

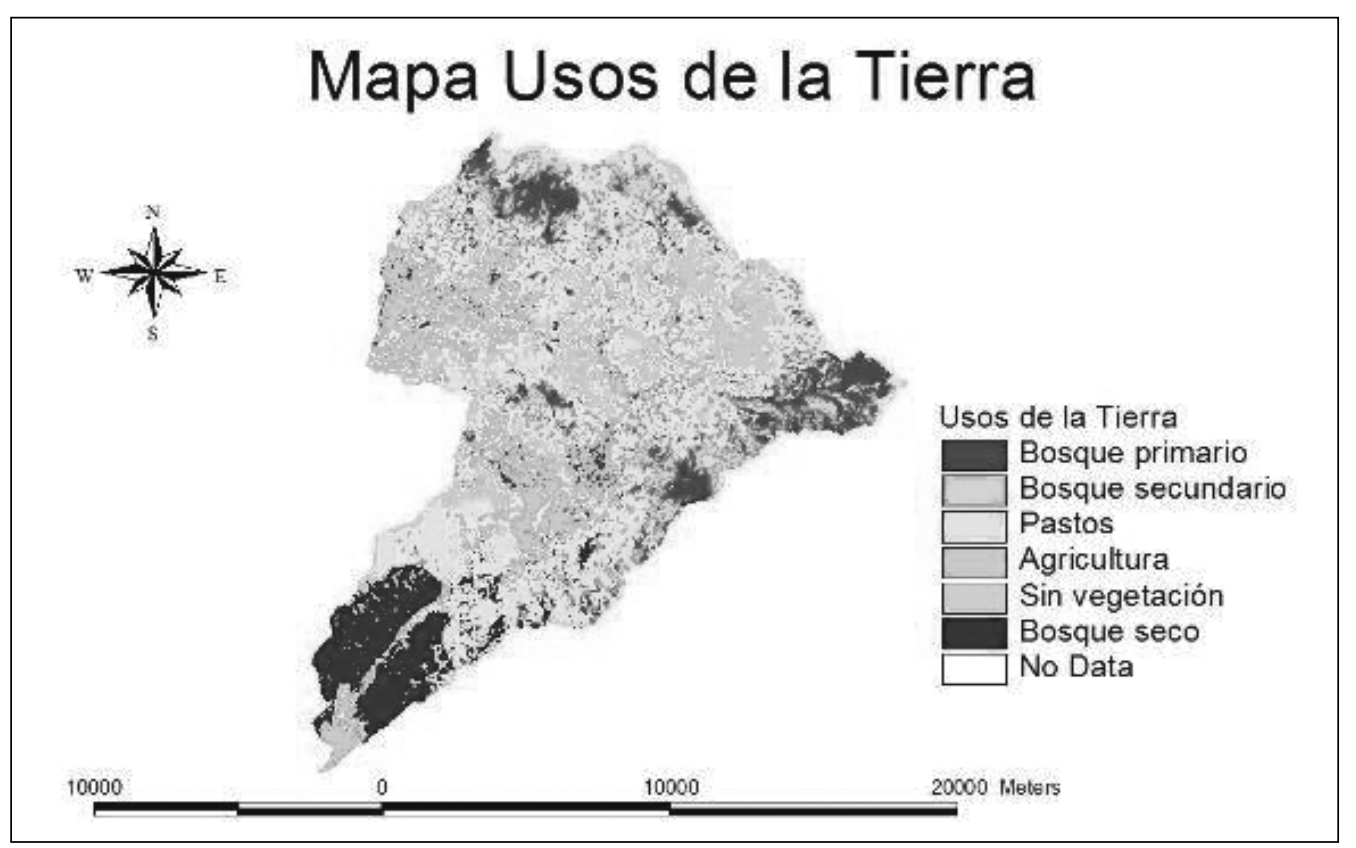


produce la misma erosión en una masa arbórea densa que en una abierta; o la que se produce en pastizales bien conservados que en pastizales degradados; o la que se produce en cultivos agrícolas con o sin prácticas de conservación. En este estudio, por la generalidad de las categorías definidas en el Mapa de Usos de la tierra de partida, no se han podido establecer más de una categoría por cada uso. Para establecer otras categorias se requeririan datos respecto a las densidades y estructura de la vegetación.

Tabla 4. Usos de la tierra clasificados

\begin{tabular}{|c|l|l|}
\hline Clase & Usos de la tierra & Riesgo de erosión \\
\hline 1 & Bosque primario & Muy bajo \\
\hline 2 & Bosque secundario & Bajo \\
\hline 3 & Pastos & Medio \\
\hline 4 & Agricultura & Alto \\
\hline 5 & Sin vegetación & Muy alto \\
\hline
\end{tabular}

Fte. Elaboración propia

\subsection{Asignación de los usos del suelo a cada clase de riesgo de erosión}

La distinción de las dos primeras clases -bosque primario y bosque secundario- del resto es clara, ya que en general, los bosques influyen sobre el suelo protegiéndolo de la erosión, atenúan los efectos de la lluvia porque impiden que caiga con fuerza sobre el suelo y favorecen la absorción con la materia orgánica acumulada. También, la red formada por las raíces sujeta el suelo impidiendo su arrastre (FAO, 1994). Por este motivo ambos bosques se designarán con las clases 1 y 2 que se corresponden con las de menor riesgo de erosión.

Clase 1: Bosque primario, se considera que es el uso de suelo que menos riesgo de erosión genera debido a que es un bosque en su mayor parte inalterado por actividades humanas. Además, es un ecosistema más estable y por tanto con una vegetación más implantada.

Clase 2: Bosque secundario, éste se ha diferenciado del anterior y se ha clasificado en esta categoría porque provoca mayor riesgo de erosión que el bosque primario. El argumento fundamental es que un bosque secundario es una etapa de degradación del bosque primario, es habitualmente un bosque que fue primario y que tras ser degradado comienza a recuperarse. Como etapa previa al bosque maduro aún contiene elementos de bosque degradado, entre ellos una menor cantidad de estratos arbóreos y una menor cantidad de biomasa. Lo cual disminuye tanto la capacidad de retención del suelo como la resistencia y obstáculos que encuentra una gota de agua hasta llegar al suelo, lo que influye en la velocidad del impacto de la gota sobre el suelo, siendo por lo tanto mayor ésta en un bosque secundario o degradado que en uno primario.
No obstante, la estimación de erosión comparada entre ambos tipos de bosque sigue siendo a día de hoy objeto de estudio, pues hasta la fecha no se ha encontrado una documentación que nos permitiera establecer valores previos de partida para los andes peruanos.

Más difícil es estimar qué tipo de uso de suelo, pastos o cultivos protege más el suelo de la erosión. Esta decisión depende notablemente del estado y uso que se haga de los mismos. Se parte de que la Microcuenca de Mijal posee mayor extensión dedicada a cultivos (797 Ha.) que a pastos (309 Ha). Y también, que la presión agrícola es mayor que la ganadera. De este modo se define como:

Clase 3: Pastizales, este uso de suelo frena la erosión en función de su estado de conservación. Si los pastos están bien conservados el grado de protección frente a la erosión es alto. Sin embargo, pueden estar degradados por sobrepastoreo (uso demasiado intenso), ya que el ganado compacta el terreno y elimina la vegetación aumentando así la escorrentía.

Esta degradación no se da en la zona, ya que la presencia de ganado en los pastos no es abundante, por lo que se pueden considerar pastos con suficiente cobertura vegetal. Esta es la razón de clasificar los pastos en la clase 3 (riesgo medio de erosión) y no en la clase 4.

Clase 4: Agricultura, los cultivos causan un arrastre muy intenso después de la siembra hasta que las plantas protegen con su cobertura el suelo, estando éste temporalmente sin (o con poca) cobertura. Además, en estas zonas hay una fuerte influencia de las actividades del hombre como: plantar, azadonar, desherbar, cosechar, etc., que provoca una perturbación de la estructura del suelo, y por lo tanto mayor riesgo de erosión. Unido a esto se da el hecho de que la mayoría de los habitantes de la zona poseen cultivos para autoconsumo. Esto provoca que las prácticas de manejo para la conservación de suelos en los terrenos cultivados no se tengan demasiado en cuenta, puesto que su única necesidad es cultivar durante todo el año.

Estas conclusiones son extraídas de los datos obtenidos en el estudio "Erosión del suelo en los lados de la Cordillera Real en el Sur de Ecuador» ajustados a la información de las salidas de campo llevadas a cabo en la Microcuenca de Mijal.

En el estudio citado analizan el riesgo de erosión de distintos cultivos como son: café, yuca, maíz, fréjol, etc. Los resultados obtenidos son aplicables a este trabajo, ya que se trata de los mismos cultivos que se desarrollan en Mijal.

La asignación de estas clases a cada uso del suelo coincide también con los datos obtenidos en el estudio "Aplicaciones del modelo USLE/RUSLE para estimar pérdidas de suelo por erosión en Uruguay y la región sur de la cuenca del río de la Platan donde se concluye que en los bosques se produce 64 veces menos erosión que en los pastizales, y que la agricultura continua con laboreo convencional presenta un 
incremento de 15 veces de erosión, respecto a la situación de pasto natural.

Clase 5: Sin vegetación, cuando el terreno está desnudo el efecto de degradación de suelos es más directo y severo porque cada año el suelo carece de cobertura vegetal que le proteja.

El Mapa de Uso de la tierra clasificado (Figura 12) es el resultado de clasificar el Mapa de Usos de la tierra según clases definidas en la Tabla 4. Previamente fue necesario transformar las imágenes Landsat en el mapa de usos de suelos,

\subsection{Obtención del mapa de Riesgo de erosión}

Para estimar el riesgo de erosión se combinó en una matriz de $5 \times 5$ las clases definidas para las pendientes y para los usos del suelo (véase Tabla 5). La combinación de valores en la matriz se realiza del siguiente modo:

- Cuando coincida el valor de las dos variables (pendientes y uso del suelo), el valor final de riesgo de erosión será el mismo que el de las variables. Por ejemplo, pendiente $=1$ y uso del suelo $=1$, el riesgo de erosión tomará el valor 1 .

- Cuando sea posible, se tomará el valor intermedio entre las dos variables. Por ejemplo, si la pendiente $=3$ y el uso del suelo=1, entonces el riesgo de erosión será igual a 2 .

- Si hay varios valores intermedios, se optará por el número intermedio de mayor valor. Por ejemplo, si la pendiente $=1$ y el uso del suelo $=4$, (los valores inter-
TABLA 5. Riego de erosión: Matriz combinación pendientes con usos del suelo.

\begin{tabular}{|c|c|c|c|c|c|c|c|}
\hline & \multicolumn{7}{|c|}{ PENDIENTES } \\
\hline \multirow{4}{*}{$\begin{array}{c}\text { USOS } \\
\text { DEL }\end{array}$} & $\begin{array}{c}\text { Riego } \\
\text { de erosión }\end{array}$ & Clases & 1 & 2 & 3 & 4 & 5 \\
\cline { 2 - 9 } SUELO & Muy bajo & 1 & 1 & 2 & 2 & 3 & 3 \\
\cline { 2 - 9 } & Bajo & 2 & 2 & 2 & 3 & 3 & 4 \\
\cline { 2 - 9 } & Medio & 3 & 2 & 3 & 3 & 4 & 4 \\
\cline { 2 - 9 } & Muy Alto & 4 & 3 & 3 & 4 & 4 & 5 \\
\hline
\end{tabular}

Fte. Elaboración propia

medios posibles son el 2 y el 3), tomando el valor intermedio más alto el valor de riesgo de erosión es 3.

- Finalmente, si no hay valores intermedios entre las dos variables, el valor final de riesgo de erosión coincidirá con el valor más alto de cualquiera de las dos variables. Por ejemplo, si la pendiente $=4$ y el uso del suel $0=5$, el valor de riesgo de erosión es 5 . Con este hecho se da la misma importancia a las dos variables, y se considera el principio de prevención.

El Mapa de Riesgo de erosión (Figura 13) es el resultado de la combinación del Mapa de Pendientes clasificado y el Mapa de Usos

\subsection{Zonificación del riesgo de erosión}

Con el propósito de que el Mapa de Riesgo de erosión obtenido pueda ser usado como insumo en la planificación

Figura 12. Mapa de Usos de la tierra clasificado del Distrito de Chalaco.

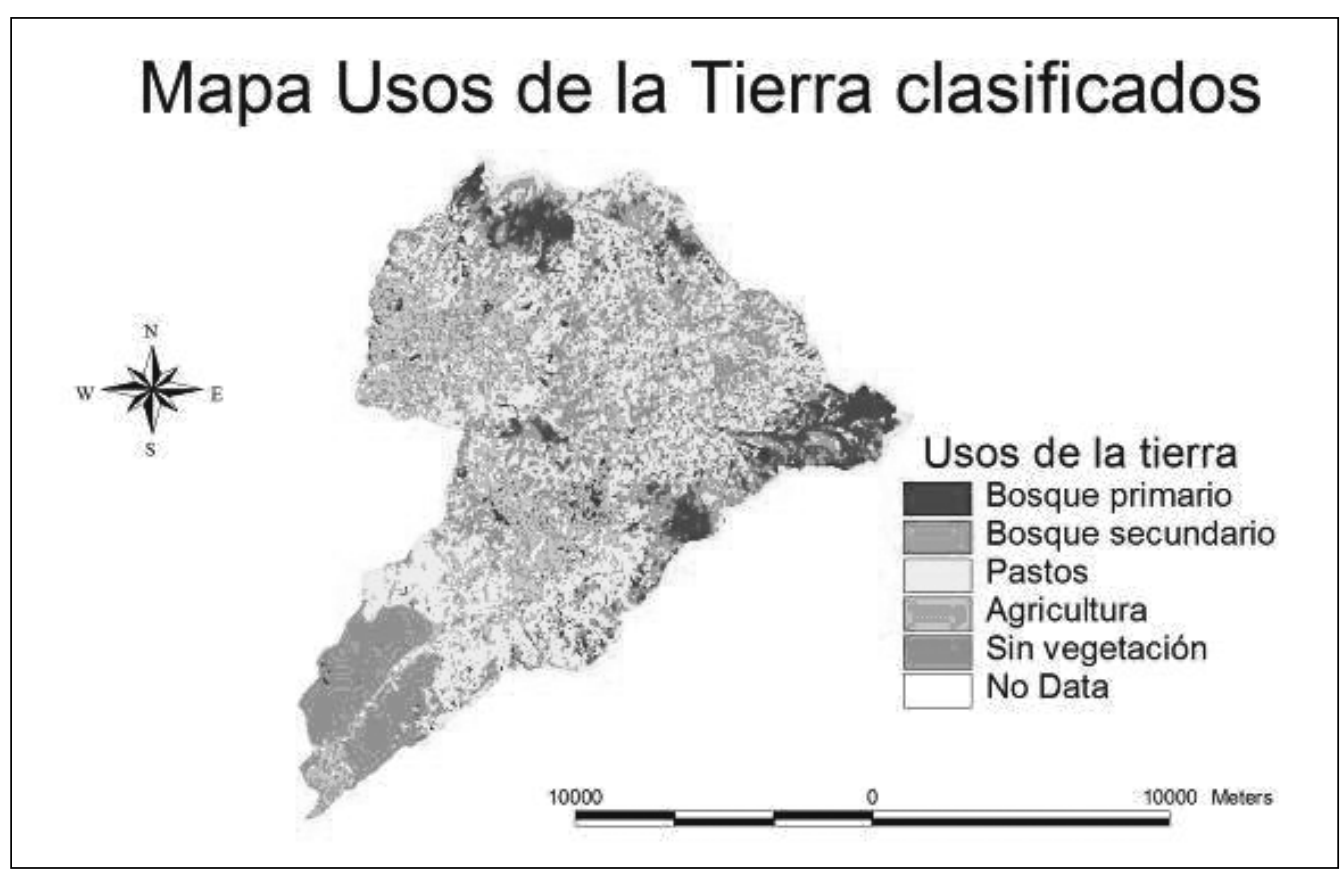




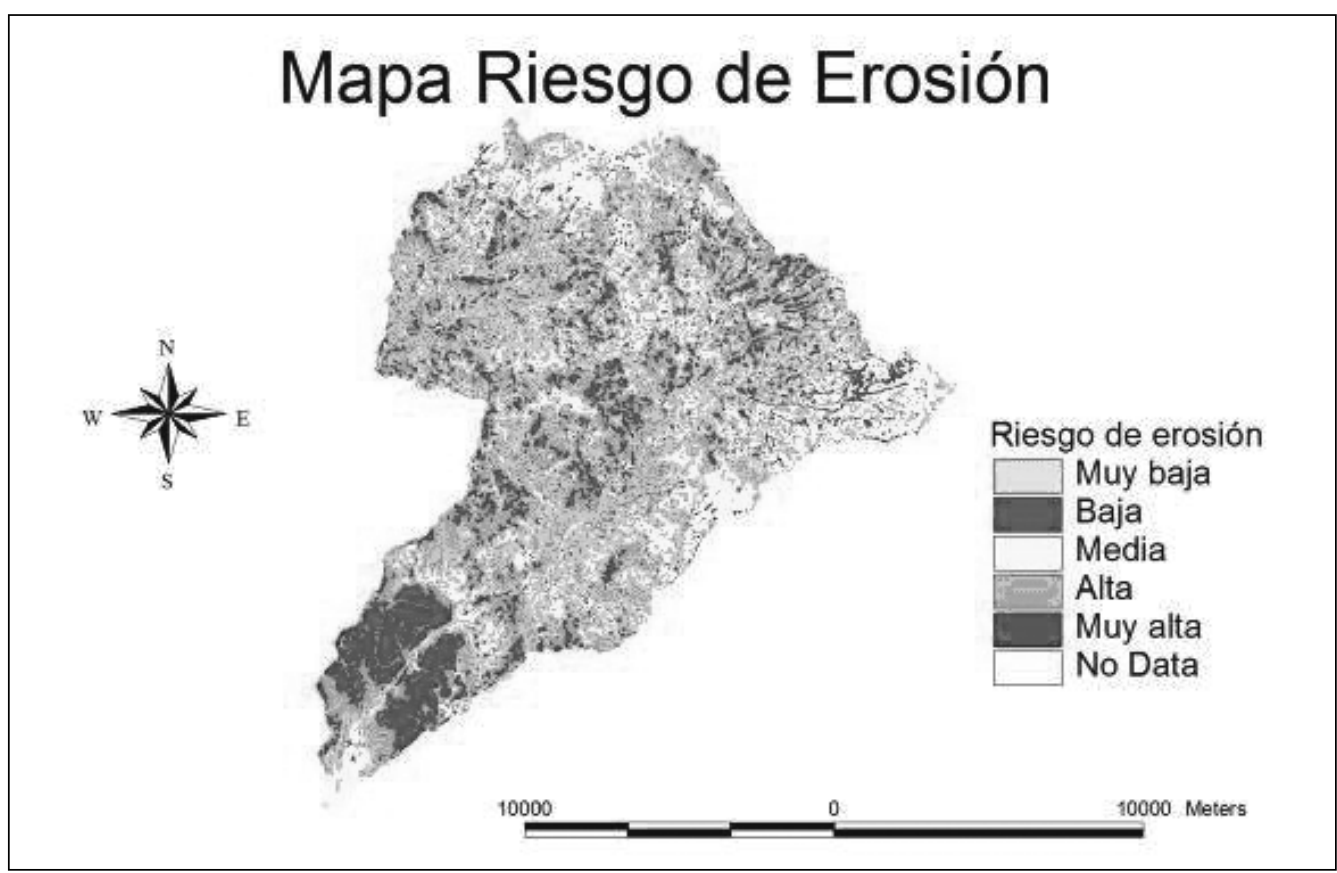

participativa a nivel local se ha combinado con el Mapa Político (Figura 14) quedando delimitado el riesgo de erosión en función de las cinco Microcuencas del distrito de Chalaco y los 8 caseríos que conforman la Microcuenca de Misal

\subsection{Riesgo de erosión en función de la erodibilidad del suelo}

El riesgo de erosión del suelo es la mayor o menor susceptibilidad del material edáfico a ser disgregado y transportado por los agentes erosivos. Aunque la resistencia del suelo a la erosión depende de su textura, estructura, capacidad de infiltración, etc., también existen índices que relacionan directamente el riesgo de erosión del suelo con el sustrato litológico (Aguiló, M. et al, 2000).

Este trabajo se basará en estos índices debido a la carencia de información de otros datos relacionados con el suelo.

Asumiendo esta limitación en la información, se empleará el tipo de sustrato litológico como indicador del riesgo de erosión potencial. Esto es válido porque las rocas intervienen en el proceso de formación de los suelos y son un componente del mismo, por tanto, si el tipo de roca es más o menos erosionable es esperable que ese suelo también lo sea.
Como se puede ver en el mapa geológico (Figura 15), los sustratos litológicos presentes en la Microcuenca de Mijal son los siguientes:

KT-t-a: estas siglas corresponden a un tipo de roca intrusiva que es la tonalita. Es una roca ígnea, cuyo grado de erosión potencial es muy bajo (Aguiló, M. et al, 2000).

$\mathrm{KT}-\mathrm{t}, \mathrm{d}-\mathrm{p}$ : estas iniciales en la leyenda hacen referencia a una formación de tonalita, diorita y pambarumbe. La diorita se corresponde con una roca ígnea de origen plutónico, y su erosión potencial se establece como muy baja (Aguiló, M. et al, 2000).

Pe-co: estas siglas hacen referencia a un Complejo de Olmos. Esto es una secuencia de esquistos. El esquisto es un tipo de roca metamórfica de grado medio, cuyo grado de erosión potencial se define como medio (Aguiló, M. et al, 2000).

El Mapa Geológico con tres tipos de formaciones (Tabla 6) se reclasifica en dos clases atendiendo al riesgo de erosión. De manera que la categoría 1 y 2 se agrupan en la clase $0, y$ la categoría 3 se establece como clase 1 (Tabla 7).

Clase 0: tonalitas, dioritas y pambarumbe son agrupadas en esta clase, ya que todas son rocas ígneas que presentan un grado de erosión potencial muy bajo, y por tanto no considerable.

Figura 14: Obtención del Mapa Riesgo de erosión zonificado.

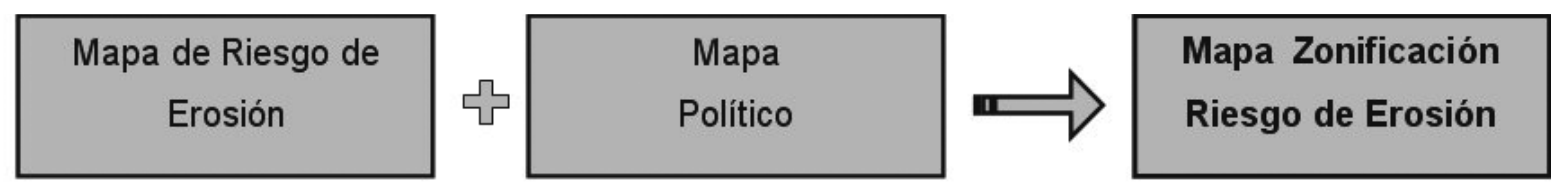


Figura 15: Geología de la Microcuenca de Mijal.

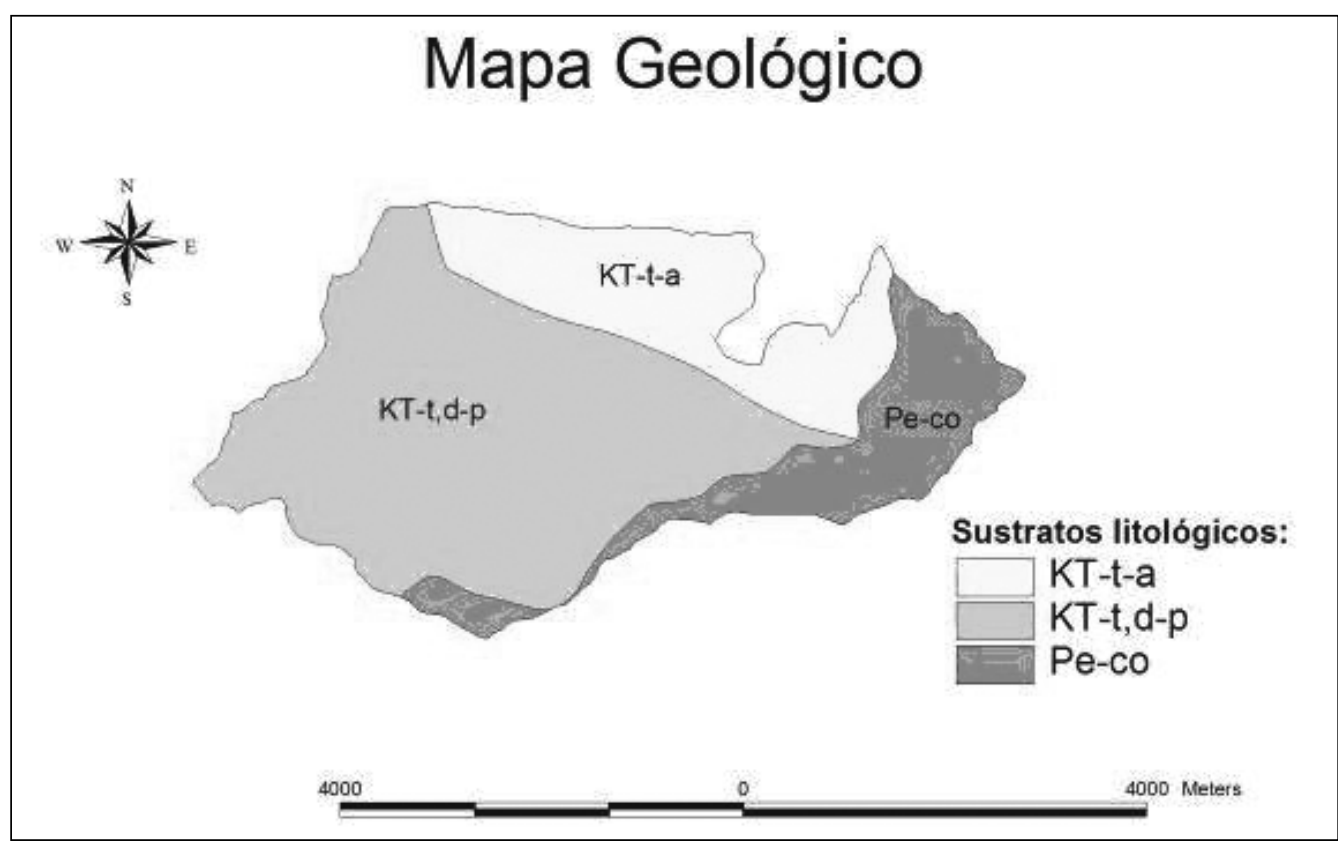

TABLA 6. Formaciones geológicas de la Microcuenca de Mijal

\begin{tabular}{|c|c|c|}
\hline Categoría & Geología & Nombre \\
\hline 1 & KT-t-a & Tonalita, altamisa \\
\hline 2 & KT-t,d-p & Tonalita, diorita, pambarumbe \\
\hline 3 & Pe-co & Complejo de olmos \\
\hline
\end{tabular}

Fte. Elaboración propia.

Clase 1: esquistos, es un tipo de roca metamórfica y por las características de éstas su grado de erosión potencial es medio, por ello este tipo de roca será tenida en cuenta a la hora de estimar el riesgo de erosión.
TABLA 7. Reclasificación del mapa geológico.

\begin{tabular}{|c|c|c|}
\hline Clase & Geología & Riesgo de erosión \\
\hline 0 & $\begin{array}{c}\text { KT-t-a } \\
\text { KT-t,d-p }\end{array}$ & No significativo \\
\hline 1 & Pe-co & Significativo \\
\hline
\end{tabular}

Fte. Elaboración propia.

Una vez clasificado el Mapa Geológico (Figura 16) en dos clases se procede a sumarlo con el mapa de riesgo de erosión. El resultado es una matriz de 5 columnas por 2 filas (Tabla 8) con los valores correspondientes a la suma

Figura 16. Mapa Geológico clasificado de la Microcuenca de Mijal.

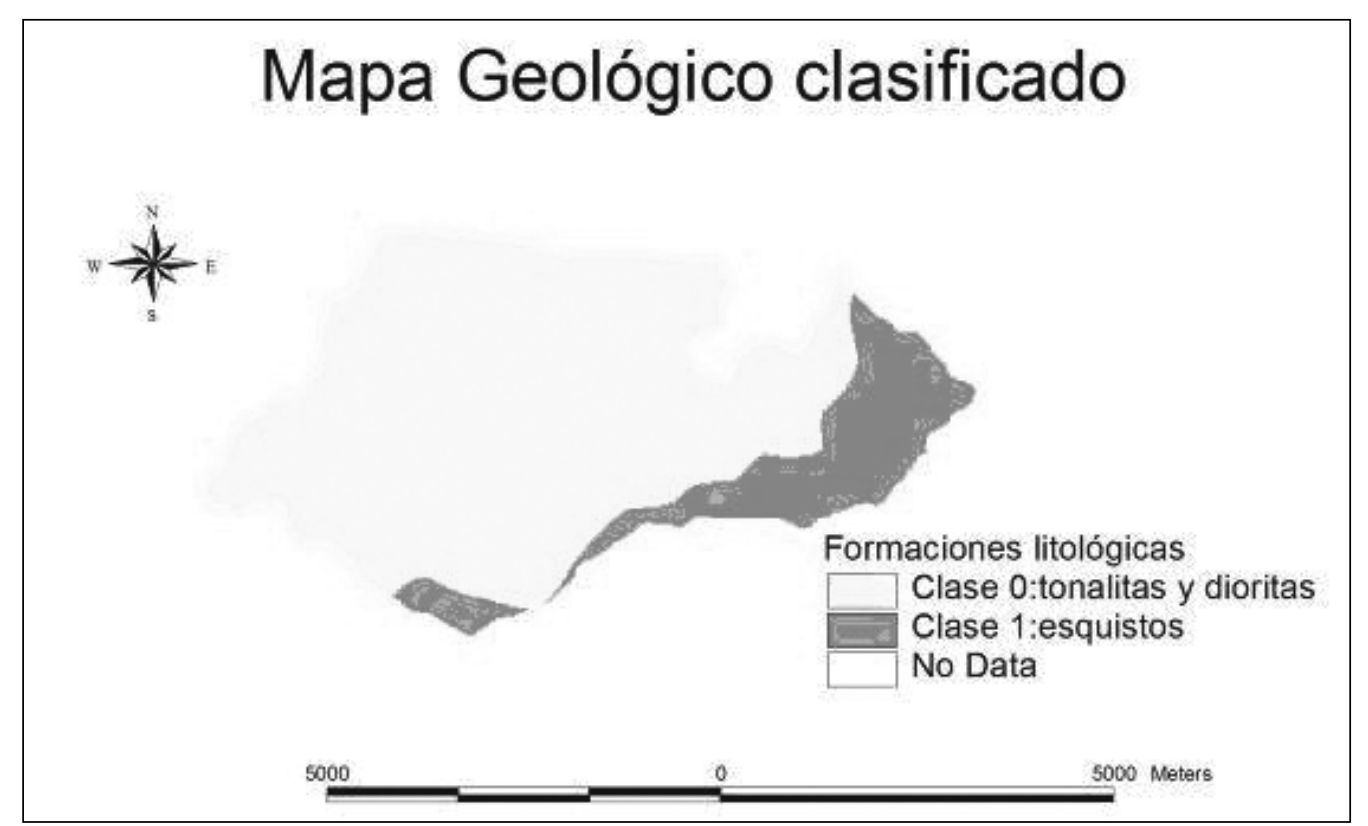


de las dos variables consideradas (geología y riesgo de erosión).

En el mapa resultado surgirán zonas con un incremento de una unidad en el valor de riesgo de erosión por estar situadas en suelos con esquistos; sin embargo las zonas ubicadas en suelos con rocas de la clase 0 mantendrán su valor respecto al riesgo de erosión.

Como puede observarse en la Tabla 8, si el riesgo de erosión es muy alto (clase 5 ) y además se ubica en una zona con presencia de esquistos (clase 1), surge una nueva clase

TABLA 8. Matriz suma del mapa de riesgo de erosión y mapa geológico clasificado.

\begin{tabular}{|c|c|c|c|c|c|c|}
\hline & \multicolumn{6}{|c|}{$\begin{array}{c}\text { MAPA ZONIFIACIÓN RIESGO EROSIÓN } \\
\text { (PENDIENTES + USOS DEL SUELO) }\end{array}$} \\
\hline MAPA & & 1 & 2 & 3 & 4 & 5 \\
\cline { 2 - 7 } $\begin{array}{c}\text { GEOLOGICO } \\
\text { RECLASIFICADO }\end{array}$ & 0 & 1 & 2 & 3 & 4 & 5 \\
\cline { 2 - 7 } & 1 & 2 & 3 & 4 & 5 & $6(5)$ \\
\hline
\end{tabular}

Fte. Elaboración propia

de riesgo de erosión, la clase 6. Debido a que en todo el trabajo se han considerado sólo 5 clases de riesgo de erosión, la clase 6 se identifica como clase 5 (riesgo de erosión muy alto).

Los pasos seguidos para la consecución del Mapa Riesgo de erosión final son los mostrados en la Figura 17 En primer lugar, se clasifica el Mapa Geológico; posteriormente se suma con el Mapa de zonificación de riesgo de erosión, obteniendo finalmente el Mapa de Riesgo de Erosión Final (Figura 27).

\subsection{Discusión del método}

Para aplicar el SIG en la Microcuenca de Mijal se ha elaborado un modelo simple pero eficiente. Si bien para futuras aplicaciones sería aconsejable variar los criterios y las clases de cada criterio para evaluar la variación en el resultado final.

Además, el método propuesto en este trabajo para estimar el riesgo de erosión puede ser mejorado incluyendo otra serie de información, como por ejemplo datos de climatología, profundidad del suelo, textura del suelo, etc. De este modo los resultados obtenidos podrían adecuarse más a la realidad.

No obstante, la manera más precisa para calcular el riesgo de erosión es la aplicación de un modelo cuantitativo que aporte datos numéricos de la cantidad de pérdida de suelo por unidad de tiempo y espacio. La carencia de infor- mación presente en la zona sobre los factores que influyen significativamente en el proceso de erosión, hace que la aplicación de un modelo cuantitativo no sea factible en un futuro cercano aunque los trabajos van encaminados a la obtención de valores que nos permitan caracterizar estos valores.

\section{RESULTADOS}

En el presente apartado se van a mostrar los resultados obtenidos respecto al riesgo de erosión. Para que el análisis sea sencillo y de fácil comprensión se divide el apartado en cinco puntos:

1. Análisis del riesgo de erosión en todo el Distrito de Chalaco.

2. Análisis de los dos factores que han condicionado ese riesgo de erosión (pendientes y usos del suelo).

3. Zonificación del Distrito de Chalaco en microcuencas, se compara el riesgo de erosión entre ellas.

4. Análisis del riesgo de erosión en una de esas microcuencas, la Microcuenca de Mijal. Se divide esta microcuenca en sus correspondientes caseríos, haciendo una comparación entre los mismos.

5. Análisis del riesgo de erosión obtenido cuando se tiene en cuenta la geología.

De este modo se realiza un análisis en tres niveles territoriales decrecientes en extensión: Distrito de Chalaco, Microcuenca de Mijal y caseríos de la Microcuenca de Mijal.

\subsection{Riesgo de erosión en el Distrito de Chalaco}

A la vista de los resultados obtenidos (Figura 18) se puede comprobar que el riesgo de erosión en todo el Distrito de Chalaco es elevado. Más de la mitad de la zona muestra un riesgo de erosión alto (un 48\%) o muy alto (un 15\%). Además, la extensión ocupada por zonas con riesgo de erosión medio es muy superior (30 veces más) a la ocupada por zonas con riesgo de erosión aceptable (éstas se consideran las que tienen riesgo de erosión bajo o muy bajo).

Estos resultados son coherentes si se analiza por separado la inclinación de las pendientes y los tipos de usos del suelo en la zona. Ambos factores son los que se han tenido en cuenta para estimar el riesgo de erosión.

En cuanto a las pendientes (Figura 19), éstas alcanzan inclinaciones muy acusadas, estando mayoritariamente com-

FIgURA 17. Obtención del Mapa de Riesgo de erosión final.

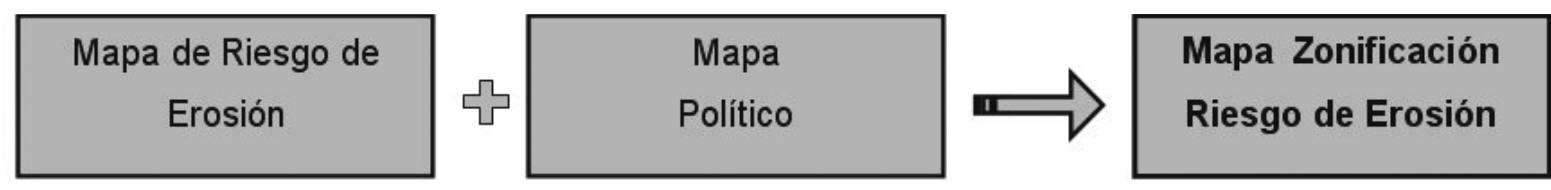




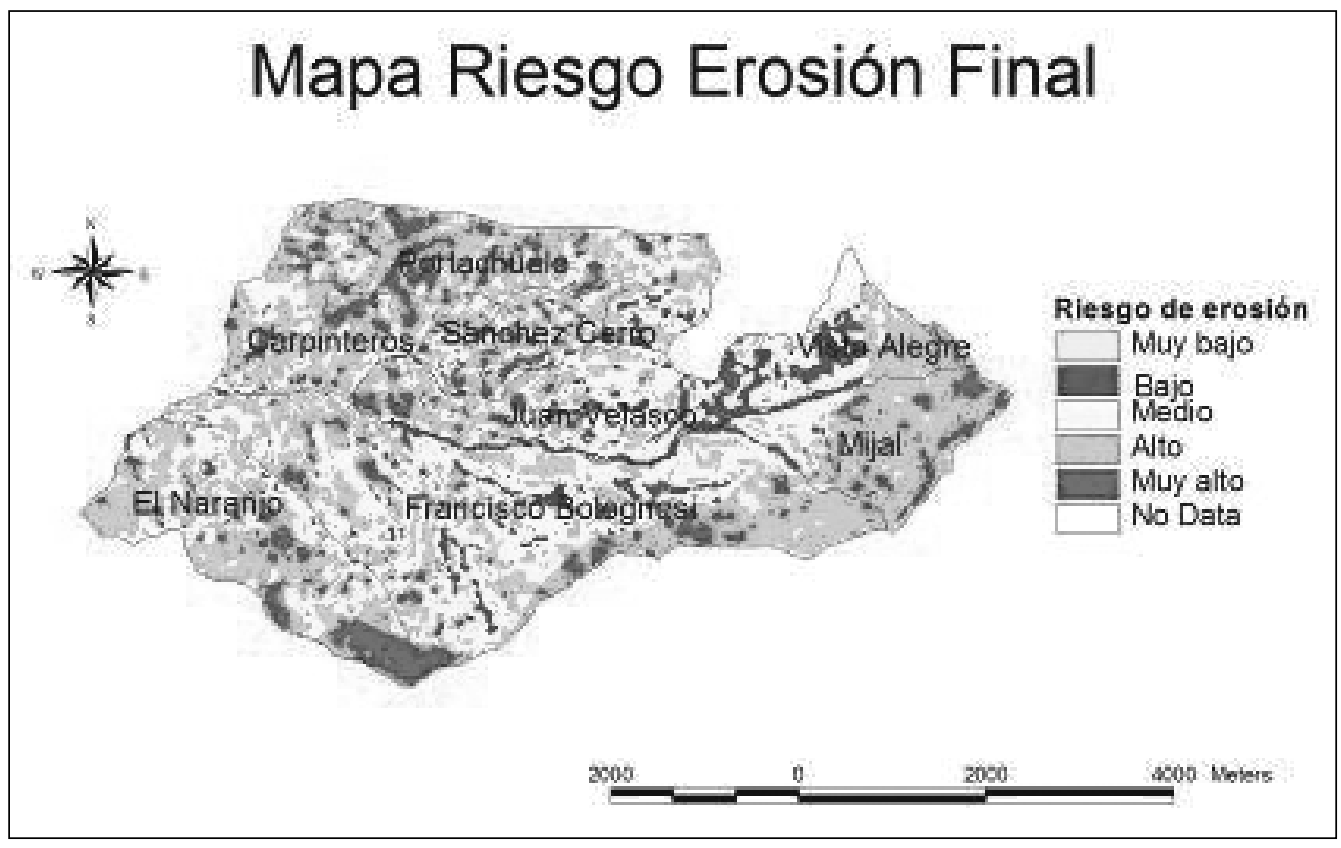

FiguRA 18. Porcentajes de riesgo de erosión en el Distrito de Chalaco.

Rlesgo de erosı́ón en el distrito de Chalaco
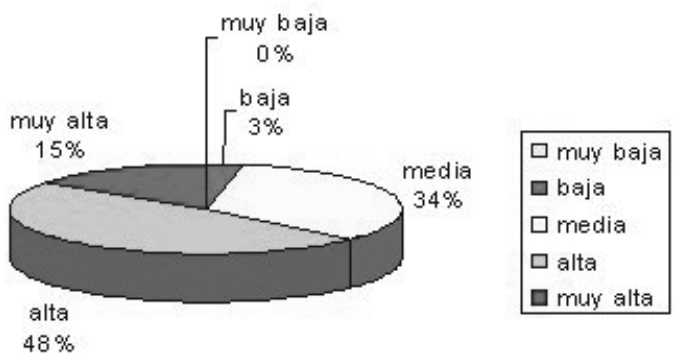

$\square$ muy alta

prendidas entre el 20 y $60 \%$ y superiores al $60 \%$. Sin embargo, las pendientes planas o casi planas son poco frecuentes en todo el distrito, representado ambos intervalos (0-10 $\%$ y $10-20 \%$ sólo un $8 \%$ en toda la zona.

Si se analizan los usos del suelo (Figura 20), se comprueba que el uso del suelo más extendido en el Distrito de

FIGURA 19. Porcentajes de intervalos de pendientes en Chalaco.

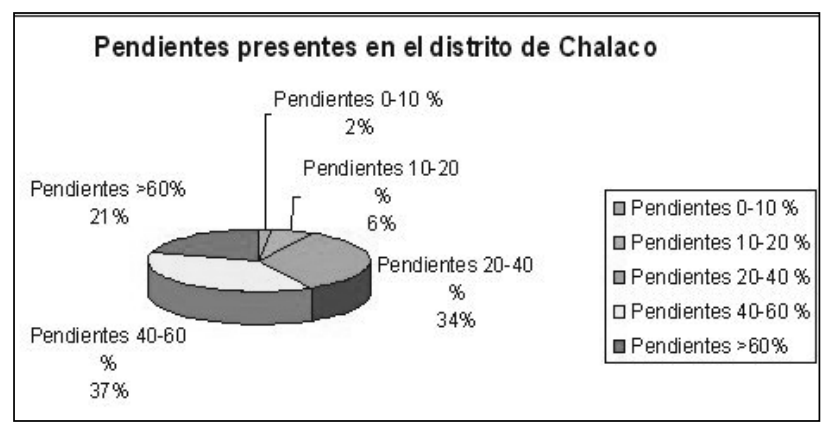

Figura 20. Porcentajes de usos del suelo en Chalaco.

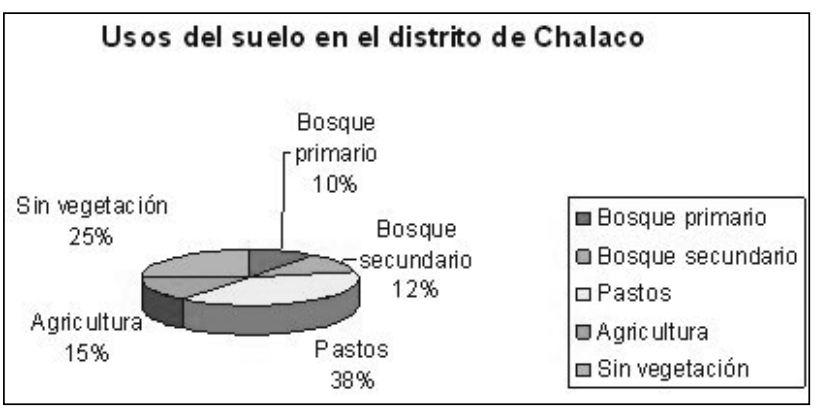

Chalaco es el pastizal (38\%). A esto se suma que una gran parte del territorio está desprovisto de vegetación (25\%). Esta situación contribuye negativamente a incrementar el riesgo de erosión junto con la escasa extensión de suelo cubierto por bosque. Es notorio el bajo porcentaje de tierra destinado a agricultura, tan sólo un 15\%, lo cual no se corresponde con lo observado en las visitas de campo.

La conjunción de pendientes abruptas y usos de suelo que favorecen la erosión o escasos usos de suelo conservadores de suelo, demuestra que el riesgo de erosión en la zona sea en general elevado.

\subsection{Riesgo de erosión en las microcuencas de Chalaco}

El siguiente mapa (Figura 21) permite estudiar el riesgo de erosión que tiene cada una de las microcuencas que forman el distrito de Chalaco.

Particularizando en el riesgo de erosión que posee cada microcuenca se concluye que es la Microcuenca de Nogal la 
Figura 21: Mapa zonificación del Riesgo de Erosión en el Distrito de Chalaco.

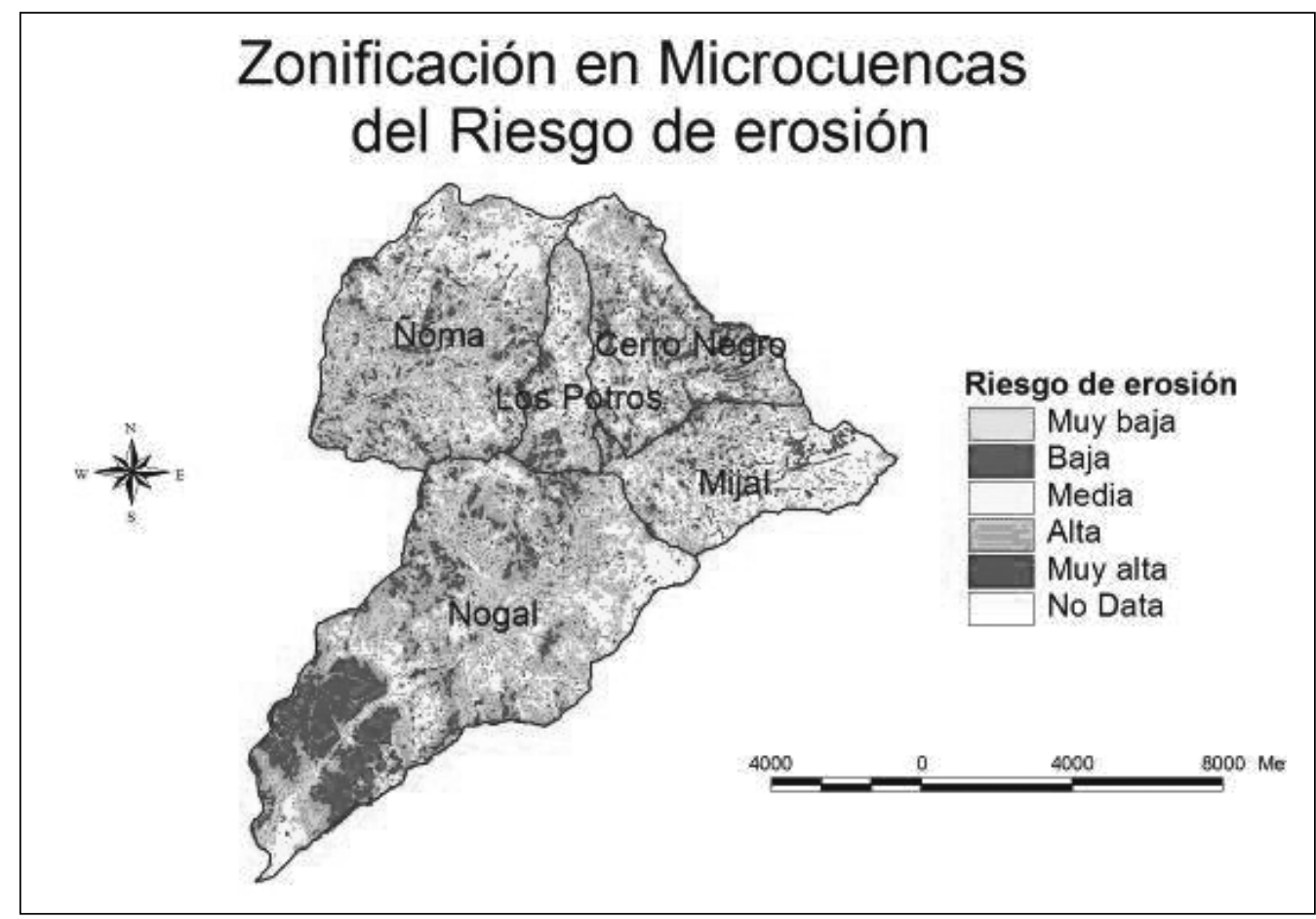

que muestra con diferencia, mayor área de zonas con un riesgo de erosión muy alto-alto. En las demás microcuencas, como en la de Ñoma, Los Potros, Cerro Negro, y en menor medida, la de Mijal, también se localizan zonas con riesgo de erosión muy alto, pero en esto caso prevalece un riesgo de erosión alto.

Otro aspecto a considerar es la extensión de las machas con un determinado riesgo de erosión. Cabe destacar la mancha de gran tamaño y homogénea que se observa en la microcuenca de Nogal y que presenta un riesgo de erosión muy alto, y también la mancha con riesgo de erosión alto que se localiza en la microcuenca de Ñoma; en las demás microcuencas prevalecen manchas aisladas y de menor extensión.

\subsection{Riesgo de erosión en la microcuenca de Mijal}

Cuando los resultados de riesgo de erosión se examinan para el caso concreto de la Microcuenca de Mijal (Figura 22) se observa que aunque al igual que ocurría en todo el Distrito de Chalaco, el riesgo de erosión sigue siendo elevado (el 40\% de la microcuenca tiene un riesgo de erosión alto o muy alto), aunque ya no lo es tanto como antes. Esto puede ser debido a que la Microcuenca de Mijal es la microcuenca de Chalaco con mayor área de bosque primario y bosque secundario, por no decir que este tipo de uso se reduce prácticamente a esta microcuenca. Este hecho hace que disminuya su riesgo de erosión de alto a medio en más de la mitad de la microcuenca. A pesar de poseer bosques (uso del suelo que dismi-
FiguRA 22. Riesgo de erosión en la Microcuenca de Mijal.

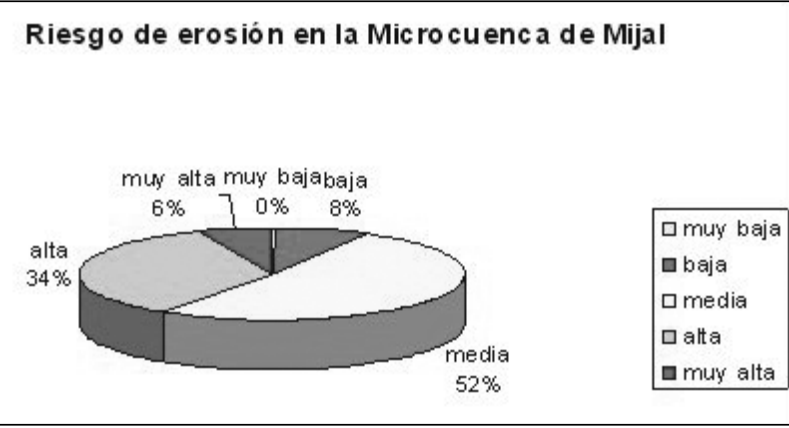

nuye la erosión), son pocas las zonas con rangos de riesgo de erosión bajos, ya que esta zona tiene pendientes muy acusadas que merman el efecto beneficioso respecto a la erosión del bosque.

\subsection{Riesgo de erosión en los caseríos de la microcuenca Mijal}

El siguiente mapa (Figura 23) permite comparar el riesgo de erosión que presentan los ocho caseríos que conforman la Microcuenca de Mijal.

Haciendo un análisis de los resultados de riesgo de erosión obtenidos en los caseríos de la Microcuenca de Mijal, se pueden deducir varias cuestiones. La primera de ellas hace referencia a la presencia en todos los caseríos de manchas pequeñas y aisladas que indican riesgo de erosión. La segunda hace referencia a la localización de las áreas con dis- 
FIGURA 23. Mapa zonificación del Riesgo de Erosión en la Microcuenca de Mijal

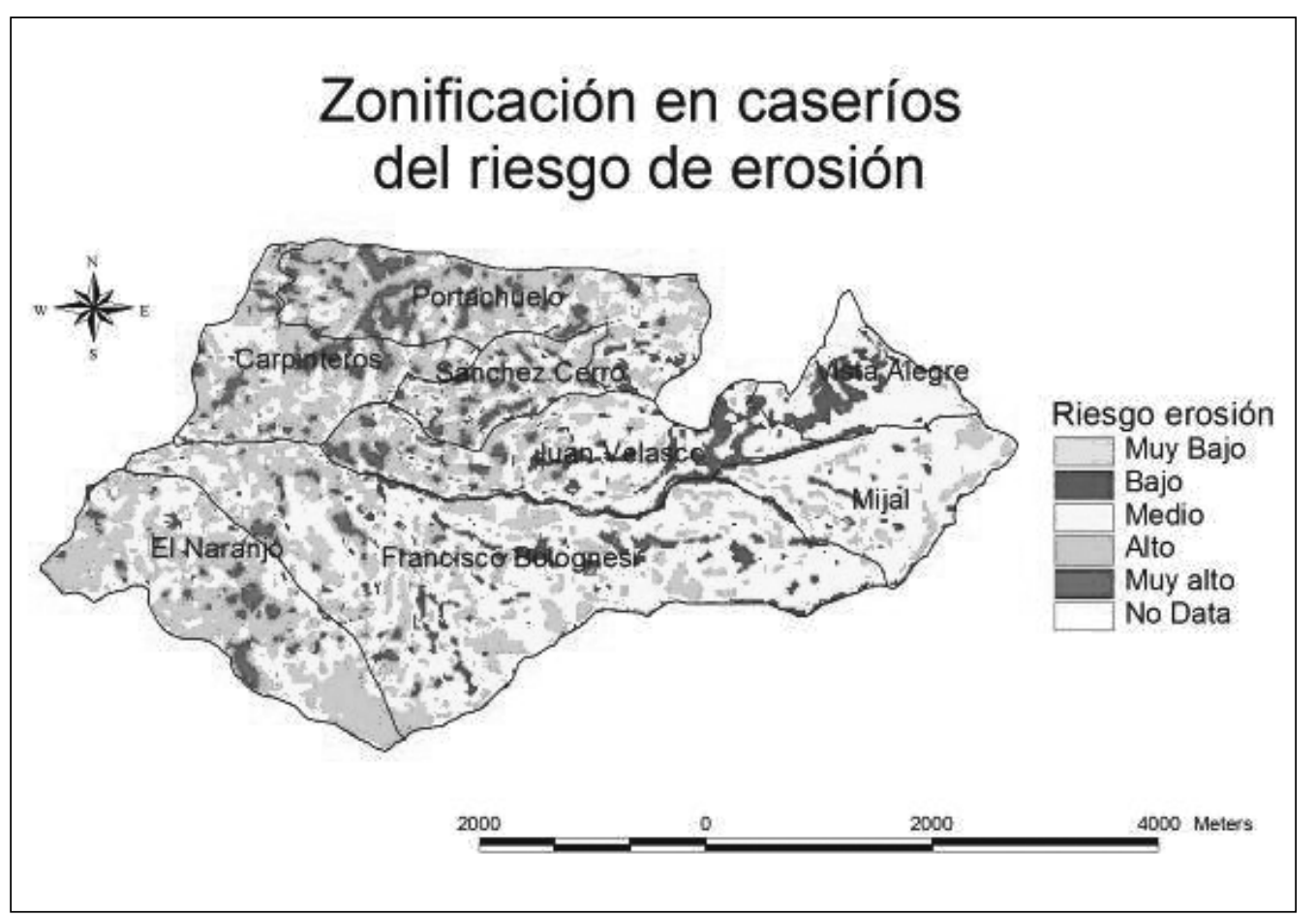

tinto riesgo de erosión. Se observa que las zonas con riesgo de erosión medio o bajo se localizan en la zona alta de la microcuenca, conformada por los caseríos de Vista Alegre, Laguna de Mijal y parte del caserío de Juan Velasco. Sin embargo, las zonas con mayor riesgo de erosión se dan en los caseríos de Portachuelo, Carpinteros, Sánchez Cerro, Juan Velasco y Naranjo, que son los que conforman la parte media-baja de la Microcuenca de Mijal.

En estos últimos caseríos predomina un tipo de uso perjudicial para el suelo. El caserío de Portachuelo es el que muestra mayor riesgo de erosión (predominan manchas con riesgo de erosión muy alto y alto). Esto es debido a que más de la mitad de su extensión carece de vegetación y el resto se destina a uso agropecuario, ambos usos se practican en un terreno con un rango de pendientes entre el 20 y el $60 \%$.

El caserío de Sánchez Cerro muestra un riesgo de erosión similar al de Portachuelo, pero se diferencian en que Portachuelo presenta manchas de mayor extensión y Sánchez Cerro manchas pequeñas y aisladas.

Por otro lado, los caseríos de Carpinteros, el Naranjo y la parte occidental de Juan Velasco coinciden en presentar un predominio de riesgo de erosión alto, reduciéndose las zonas con riesgo de erosión muy alto a favor de las áreas con un riesgo de erosión medio. Esta disminución es el resultado de la existencia de menos zonas con pendientes entre el 40 y el $60 \%$, aumentando aquellas de pendientes comprendidas entre el 20 y el $40 \%$. Además, también se puede comprobar que las manchas sin vegetación son minoritarias frente a las destinadas a agricultura y a pastos. Ambas cosas hacen que si bien el riesgo de erosión no deje de ser alto, ya no sea tan alto como ocurre en los caseríos de Portachuelo y Sánchez Cerro.

Cabe destacar, que el caserío el Naranjo posee manchas de gran extensión con riesgo de erosión alto, mientras que esto no sucede en los otros dos caseríos. También es en este caserío donde las manchas con riesgo de erosión muy alto son más extensas.

Francisco Bolognesi es el caserío de mayor área de la Microcuenca de Mijal, por este motivo y por la distinción de dos zonas diferenciadas respecto al riesgo de erosión, se va a analizar por separado. En primer lugar su parte occidental, en la cual predomina un riesgo de erosión un poco inferior al comentado para los caseríos anteriores. Este descenso lo origina la cobertura de sus suelos, principalmente, pastos y remanentes de bosque secundario. Las pendientes no favorecen la reducción del riesgo de erosión puesto que se hayan comprendidas entre el 20 y el $60 \%$, mostrando manchas extensas con pendientes superiores al 40\%.

Por otro lado, la parte oriental del caserío está cubierta fundamentalmente por bosque primario y bosque secundario. Por contra, el intervalo de pendientes asciende respecto al de la parte occidental, ya que la mayoría de las zonas poseen pendientes entre el $40-60 \%$ y superiores al $60 \%$. A pesar de estas abruptas pendientes, el riesgo de erosión es predominantemente medio, e incluso comienzan a aparecer pequeñas manchas alargadas con riesgo de erosión bajo.

El caserío de Laguna de Mijal, perteneciente a la zona alta de la Microcuenca de Mijal, muestra pendientes eleva- 
das (de $40 \%$ en adelante); pero como sus suelos están protegidos por grandes extensiones de bosque primario y otras de menor extensión de bosque secundario, las altas pendientes quedan compensadas dando lugar a un riesgo de erosión medio casi uniforme en toda microcuenca. No obstante, aunque todavía se siguen presenciando manchas con riesgo medio de erosión, estas son aisladas y de pequeña superficie. También, aunque muy pocas y pequeñas, se observan zonas con riesgo de erosión bajo.

Por último, el caserío de Vista Alegre y la parte oriental del caserío de Juan Velasco. Ambos coinciden en ser los únicos en los cuales las zonas con riesgo de erosión bajo son extensas y homogéneas. Aunque todavía existen zonas con riesgo de erosión medio, éstas son provocadas por las pendientes de más de $60 \%$ existentes en la zona.

Es en estos dos caseríos se alcanza este valor de erosión por las homogéneas y extensas manchas de bosque primario que alberga, además de tener pendientes con menor inclinación que las observadas en el caserío de Laguna de Mijal, comprendidas entre el 20 y $40 \%$.

\subsection{Riesgo de erosión incorporando al análisis la geología}

Finalmente, se va a comparar entre el riesgo de erosión observado cuando se tiene en cuenta la combinación de pendientes y usos del suelo, con el riesgo de erosión resultante cuando además se considera la geología.

Comparando el mapa que representa el riesgo de erosión obtenido teniendo en cuenta las pendientes y usos del suelo (Figura 23), y el mapa de riesgo de erosión final que es el que incorpora la geología (Figura 24), se observa que los únicos caseríos que han sufrido modificación son los caseríos de Laguna de Mijal, Vista Alegre y Francisco Bolognesi (Figura 25).

Figura 25. Caseríos cuyo riesgo de erosión se modificado por considerar la geología. Recorte obtenido del mapa zonificación en caseríos del riesgo de erosión (Figura 23)

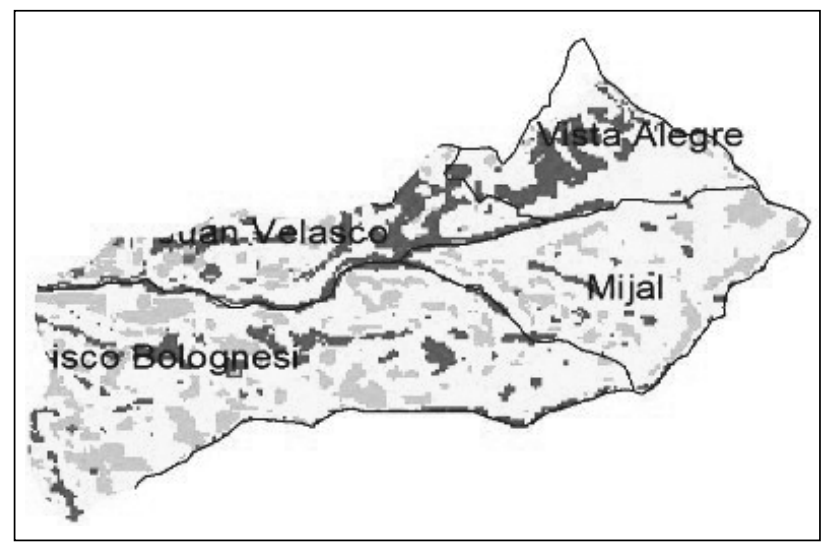

Se comprueba como la casi totalidad del caserío de Laguna de Mijal, y la parte este de los caseríos de Vista Alegre y Francisco Bolognesi aumentan su riesgo de erosión de medio a alto, y las zonas con riesgo de erosión alto pasan a tenerlo muy alto.

Analizando la Figura 26 se puede deducir que el riesgo de erosión cuando se considera la geología aumenta para valores de riesgo de erosión elevados (altos o muy alto), sin embargo se produce el efecto contrario cuando se trata de riesgos de erosión medios o bajos. Lo que ha provocado la

Figura 24. Mapa Riesgo de erosión final en la Microcuenca Mijal (Considerando la geología).

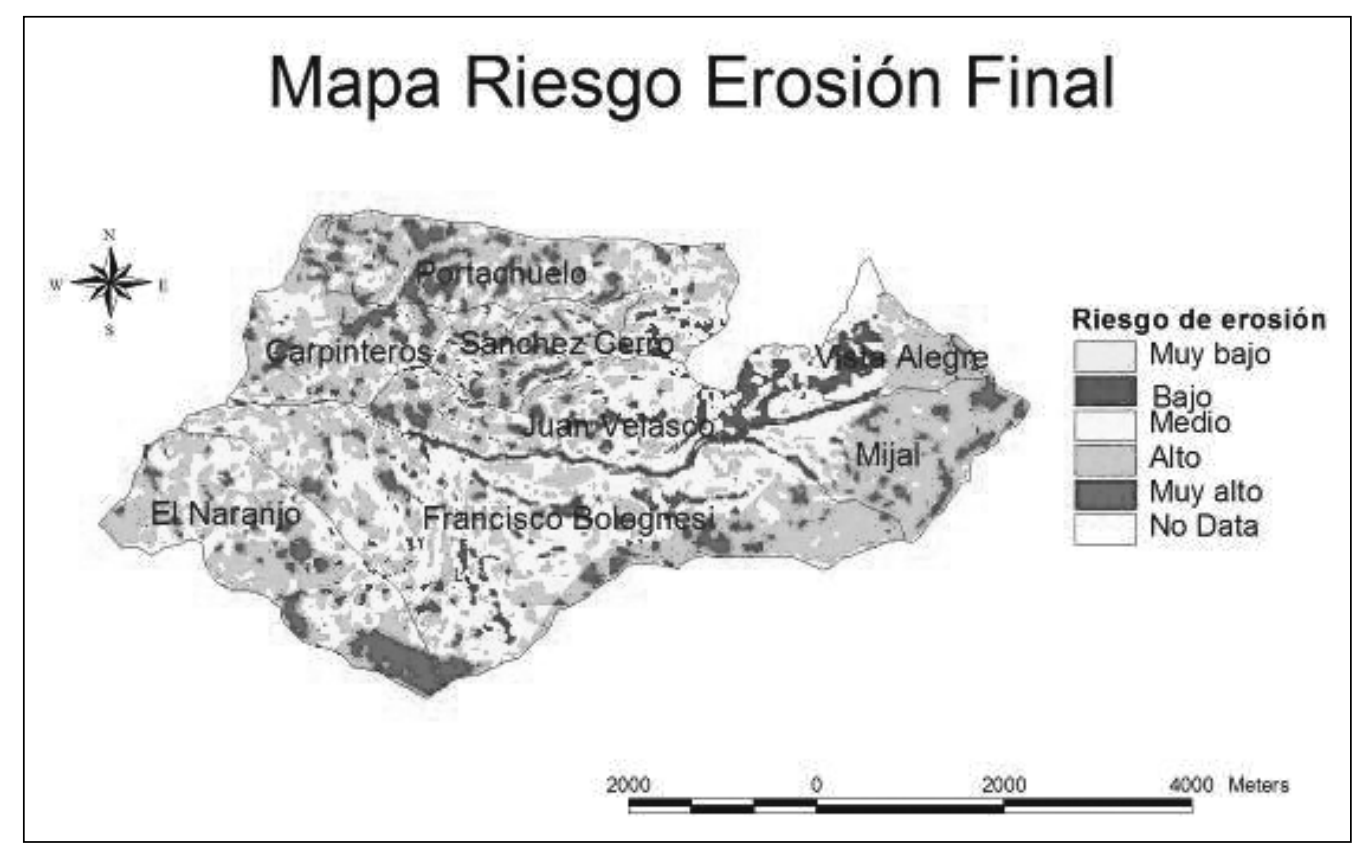


Figura 26. Comparación del efecto sobre la erosión si se considera la geología.

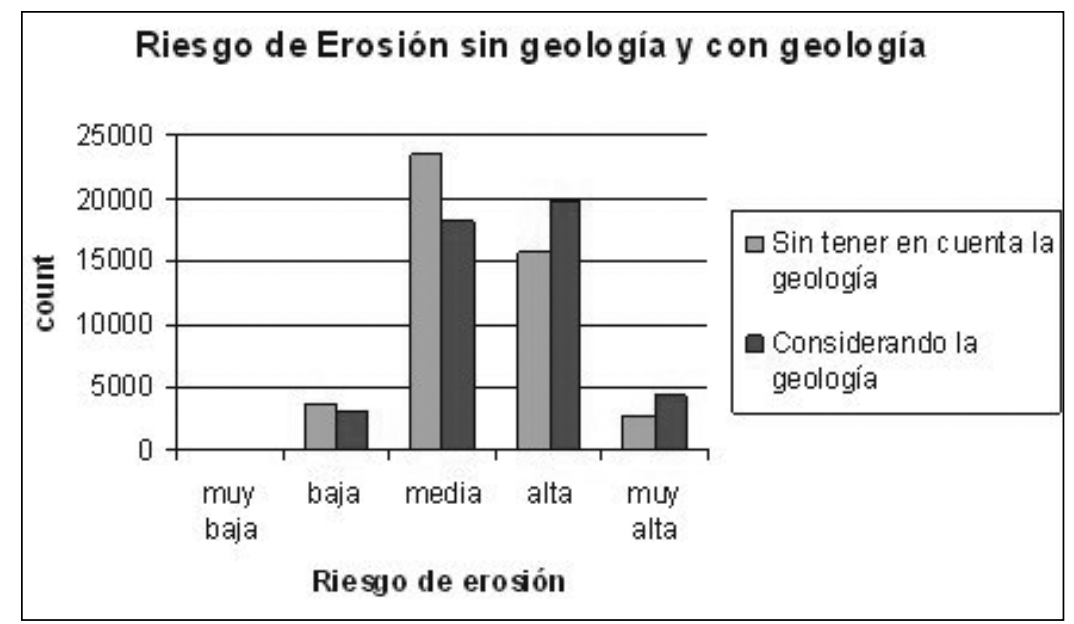

consideración de la geología es que las zonas que antes poseían un determinado riesgo de erosión pasen a tener una categoría de riesgo de erosión superior, así las zonas con riesgo de erosión medio pasan a tenerlo alto, y las altas a muy altas. Con esto se comprueba que la adición de un factor más en el análisis del riesgo de erosión es significativa, ya que es causa de variabilidad del resultado.

\section{CONCLUSIONES}

La recopilación de mapas existentes y la georreferenciación de información adicional de campo pueden resultar, a bajo coste, una base de datos útil para iniciar una discusión a nivel de microcuenca sobre la toma de decisiones en la gestión de los recursos naturales.

La secuencia de pasos que se ha presentado puede aplicarse en poco tiempo basándose en datos generalmente disponibles, 0 en datos que se obtienen de forma relativamente sencilla.

El trabajo demuestra que también con datos limitados se puede estimar el riesgo de erosión en una microcuenca sin hacer cuantificaciones exactas de la erosión. No obstante, se ha visto también que la precisión de los datos no permite que se amplie el resultado hacia una parcela.

A la vista de los resultados obtenidos, el riesgo de erosión alcanzado en la zona se puede transformar en una amenaza directa parar el agricultor. Por este motivo, se proponen sistemas y prácticas para controlar la erosión con el fin de conservar el suelo.

En base a estos estudios, las medidas de control de la pérdida de suelo más eficaces y adecuadas a la zona de estudio son las que se sugieren a continuación:

- Siembras en curvas de nivel

- Barreras vivas

- Barreras muertas

- Zanjas de infiltración
- Construcción de terrazas

- Tipo canal: son terrazas que presentan canales de sección triangulares, construidos cortando y eliminando la tierra hacia abajo. Se recomiendan para pendientes de hasta $20 \%$.

- Terrazas de banco con piedra y con cobertura vegetal: Esta práctica es recomendada para áreas con pendientes entre 20 y $40 \%$

Pese a la existencia de diferencias señaladas en el riesgo de erosión entre unos caseríos y otros, en general, la Microcuenca de Mijal presenta valores altos de riesgo de erosión, el 92\% de la zona tiene un riesgo de erosión entre medio y muy alto. Esto es debido en gran parte, a la transformación de zonas forestales a zonas agrícolas llevada a cabo por habitantes de la zona. Éstos actúan empujados por el hambre, por su escasez de recursos y por el desconocimiento de las consecuencias que ello provoca, convirtiéndose esta práctica en una solución contraproducente, originado a la larga, suelos infértiles donde no puedan cultivar nada.

Las consecuencias de la erosión no se reducen a la Microcuenca de Mijal, sino que los efectos más graves se trasladan cuenca abajo. Por ello, y debido a la situación de cabecera que tiene la microcuenca hay que conservar el bosque de Mijal.

Del análisis de todo el trabajo se concluye que la totalidad de microcuencas que conforman el distrito de Chalaco muestran un riesgo de erosión elevado por la conjunción de varias circunstancias:

- Alto grado de deforestación, sobretodo en la Microcuenca de Mijal.

- Extensión de las zonas agrícolas con cultivos como la papa que requieren mucha labranza.

- Acusadas pendientes.

- Intensas precipitaciones producidas en un corto espacio de tiempo. 


\section{REFERENCIAS BIBLIOGRÁFICAS}

AgenCia de RECURSOS VERDES (2002). Estudio de validación del desarrollo rural participativo basado en la conservación de suelos y aguas: Prácticas de conservación de suelos y aguas validadas por el Proyecto Jalda. En linea Internet. Accesible en:

http://www.green.go.jp/gyoumu/kaigai/manual/bolivia/02technical_gui de/spanish/11_validadas.pdf

Aguiló Alonso, M. et al. (2000). Guía para la elaboración de estudios del medio físico: Contenidos y metodología. Ministerio de Medio Ambiente, Madrid.

AnTEZANA, J. (2002). Calibración de los factores de erosión utilizando la ecuación universal de perfiles de suelo, revisado "RUSLE» en sistemas de producción agrícola de la cuenca Taquiña. Línea Internet. Accesible en: http://www.umss.edu.bo/epubs/earts/downloads/ 66.pdf

CSIC: Departamento de procesos geoambientales y cambio global. Los efectos del Cambio Global sobre la dinámica de procesos hidrológicos y geomorfológicos. En Línea Internet. Accesible en: www.ipe.csic.es/erosion_hidrologia/area_2.htm

CLÉRICI, C. y Garcia PrÉCHAC, F. (2001). Aplicaciones del modelo USLE/RUSLE para estimar pérdidas de suelo por erosión en Uruguay y la región sur de la cuenca del río de la Plata. Agrociencia Vol V: pag 92-103.

De HeK, S., Kiersch, B: y A. Mañon., 2004. Aplicación de Pagos por Servicios Ambientales en manejo de Cuencas Hidrográficas: lecciones de experiencias recientes en América Latina. Taller en Pago por servicios Ambientales. Barcelona.

FAO (1967). Erosion and a remedy. En línea Internet. Accesible en: http://www.fao.org/documents/show_cdr.asp?url_file=/docrep/x5382s/x5382s00.htm

FAO (1991). Ordenación de cuencas hidrográficas: Participación popular en la planificación de la ordenación de cuencas hidrográficas. En linea Internet. Accesible en: http://www.fao.org/documents /show_cdr.asp?url_file=/docrep/u1510s/u1510s00.htm

FAO (1993). El modelo USLE en Costa Rica. Basado en los trabajos presentados en el Taller sobre la Utilización de un Sistema de información geográfica (SIG) en la Evaluación de la erosión actual de suelos y la predicción del riesgo de erosión Potencial. Santiago, Chile. En línea Internet. Accesible en: http://www.fao.org/docrep/t2351s/T2351S0h.htm\#El\%20modelo\%20usle\%20en\%20Co sta\%20Rica.
FAO (1994). Erosión de suelos en América Latina. En Línea Internet. Accesible en: http://www.fao.org/documents/show_cdr.asp?url file $=/ /$ docrep/T2351S/T2351S05.htm

FAO (1997). Manual de prácticas integradas de manejo y conservación de suelos. Linea Internet. Accesible en: http://www.fao.org/ag/ags/ AGSE/agse_s/7mo/iita/iita.htm

Martín Guerrero, D. (2005). Desarrollo Sostenible en Ecosistemas de Montaña en el Perú» desde la perspectiva del enfoque LEADER y una propuesta de indicadores para su sostenibilidad. Master Internacional de proyectos de desarrollo local/rural: Análisis del Programa "

IECA. Effective erosion control (2004). En línea Internet. Accesible en: http://ieca.org/Resources/Article/ArticleEffectiveEC.asp

Martínez De Anguita, P. (en edición). Planificación física. En Guia metodológica para la elaboración de planes de desarrollo rural sostenible. Thompon. Madrid.

Martínez De Anguita, P y J.M. Beneitez. (2005). Aplicación de Sistemas de Pagos por Servicios Ambiéntales al recurso hídrico. Experiencias de desarrollo no 3. pp.38-44.

Martínez Vega, J. y Martín Lou, M. (2004). Modelos de capacidad de uso de las tierras. Métodos para la planificación de Espacios Naturales Protegidos: 63-79. Consejo superior de investigaciones científicas (CESIC).

Miranda, F. (1992). Conservación de suelos agricolas y productividad. Curso taller con técnicas de Instituciones Contrapartes de NOGUB-GOTES. Cochabamba, Bolivia.

OCAÑA, JC. (2004). Plan de manejo de la Microcuenca de Mijal. Municipalidad de Chalaco.

PEÑA, E. (2003). Programa desarrollo sostenible de ecosistemas de montaña en el Perú: Información básica de la Microcuenca de Mijal. Municipalidad de Chalaco.

Posner, J. et al. (2002). Priorizando Áreas para la Conservación de Suelos en la Microcuenca La Encañada. Línea Internet. Accesible en: http://www.cipotato.org/gis/publications/GISsoilconservation.pdf

Romero, C. y StroonsniJderB, L. (2002). Evaluación del Comportamiento del Modelo de Erosión WEPP Bajo Condiciones de los Andes: Caso La Encañada - Perú. Universidad Nacional Agraria La Molina. En linea Internet. Accesible en: www.tradeoffs.montana.edu/ pdf/WEPP.pdf

UnIVERSIDAd De PIURA (2004). Programa «Desarrollo Sostenible de Ecosistemas de Montaña en el Perú». En Linea Internet. Accesible en: http://www.udep.edu.pe/programachalaco/ 